This item was submitted to Loughborough's Research Repository by the author.

Items in Figshare are protected by copyright, with all rights reserved, unless otherwise indicated.

\title{
Effect of material, geometry, surface treatment and environment on the shear strength of single lap joints
}

PLEASE CITE THE PUBLISHED VERSION

PUBLISHER

(C) Elsevier

VERSION

AM (Accepted Manuscript)

\section{LICENCE}

CC BY-NC-ND 4.0

\section{REPOSITORY RECORD}

da Silva, Lucas F.M., R.J.C. Carbas, Gary W. Critchlow, M.A.V. Figueiredo, and K. Brown. 2009. "Effect of Material, Geometry, Surface Treatment and Environment on the Shear Strength of Single Lap Joints". figshare. https://hdl.handle.net/2134/4635. 
This item was submitted to Loughborough's Institutional Repository (https://dspace.lboro.ac.uk/) by the author and is made available under the following Creative Commons Licence conditions.

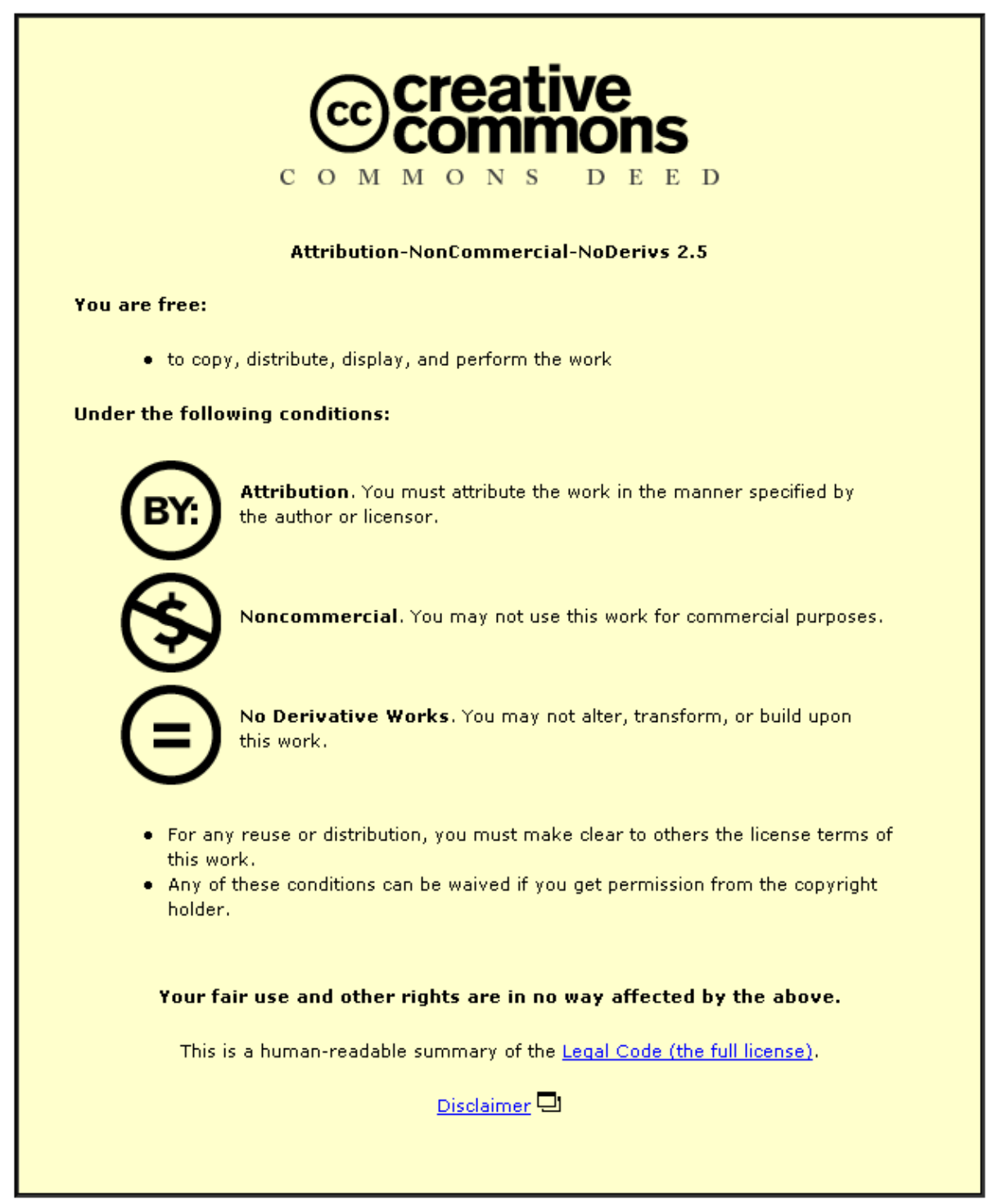

For the full text of this licence, please go to: http://creativecommons.org/licenses/by-nc-nd/2.5/ 


\title{
Effect of material, geometry, surface treatment and environment on the shear strength of single lap joints
}

\author{
Lucas F M da Silva ${ }^{1, *}$, R J C Carbas ${ }^{1}$, G W Critchlow ${ }^{2}$, M A V Figueiredo ${ }^{1}$ and \\ K Brown ${ }^{3}$ \\ ${ }^{1}$ Departamento de Engenharia Mecânica e Gestão Industrial, Faculdade de Engenharia, \\ Universidade do Porto \\ Rua Dr. Roberto Frias, 4200-465 Porto, Portugal \\ ${ }^{2}$ Institute of Surface Science \& Technology, Loughborough University \\ Loughborough, Leicestershire LE11 3TU, UK \\ ${ }^{3}$ Chemetall PLC, Denbigh Road, Bletchley, Milton Keynes MK1 1PB, UK
}

\begin{abstract}
The single lap joint is the most studied type of adhesive joint in the literature. However, the joint strength prediction of such joints is still a controversial issue as it involves a lot of factors that are difficult to quantify such as the overlap length, the yielding of the adherend, the plasticity of the adhesive and the bondline thickness. The most complicated case is that where the adhesive is brittle and the overlap long. In any case, there is still a problem that is even more difficult to take into account which is the durability. There is a lack of experimental data and design criteria when the joint is subjected to high, low or variable temperature and/or humidity. The objective of this work is to carry out and quantify the various variables affecting the strength of single lap joints in long term, especially the effect of the surface preparation. The Taguchi method is used to decrease the number of experimental tests. The effect of material, geometry, surface treatment and environment is studied and it is shown that the main effect is that of the overlap length.
\end{abstract}

\footnotetext{
${ }^{*}$ Corresponding author. Tel: +351225081706. Fax:+351225081445. Email: lucas@fe.up.pt
} 
In order to quantify the influence of the adhesive (toughness and thickness), the adherend (yield strength and thickness), the overlap, the test speed, the surface preparation and durability on the lap shear strength, the experimental design technique of Taguchi was used in the present study. An experimental matrix of eighteen tests was designed and each test was repeated three times. The influence of the eight previously-mentioned variables could be assessed using the statistical software Statview $^{\circledR}$. In this paper a simple predictive equation is proposed for the design of single lap joints.

\section{Keywords}

Adhesive; Adherend; Adhesive thickness; Overlap; Surface treatment; Durability; Lap shear strength; Statistical analysis.

\section{Introduction}

The single lap joint (SLJ) is very common in practice and simple design rules should be available for design purposes. Hart-Smith [1] proposed a chart where the joint strength is given as a function of adhesive ductility and overlap. The adherend is supposed to remain in the elastic range. This is not realistic since the substrates will

yield in many cases (e.g. aluminium or low strength steel). The ASTM 1002 standard proposes a very simple design rule to guarantee that the adherends do not yield. Adams et al. [2] developed a simple methodology to predict the joint strength. If the adhesive is very ductile, typically with more than $20 \%$ shear strain to failure, and the adherends are elastic, the joint strength is given by the load corresponding to the total plastic deformation. If the adherends yield, the joint strength is governed by the 
adherends yielding independently of the type of adhesive. For the case of a rather brittle adhesive and elastic adherends, the methodology does not work and Adams et al. [2] proposed the finite element method. The above simple design rules are very useful and can give a good prediction for many cases. There are, however, a number of parameters that are not considered in previous studies such as the adhesive thickness, the type of surface treatment and the durability.

The adhesive thickness has an important effect on the joint strength. Experience shows that the lap joint strength increases as the bondline gets thinner [3-4]. Several arguments have been proposed in the literature to explain the influence of the bondline thickness. Adams and Peppiatt [3] attribute the joint strength decrease with adhesive thickness to the fact that thicker bondlines contain more defects such as voids and microcracks. Crocombe [5] explains that as the adhesive gets thicker, the plastic spreading of the adhesive along the overlap occurs more rapidly. Interface stresses were shown to be higher for thicker bondlines by Gleich et al. [6] and da Silva et al. [4]. More recently, Grant et al. [7] explained the influence of the adhesive thickness with the bending moment. For a lap joint under tension, the longitudinal stress from the direct load and the bending moment at the edge of the overlap region create plastic strains when the steel becomes plastic and these cause failure in the adhesive. The lap joint under tension is very sensitive to adhesive thickness. There is a longitudinal stress from the direct load together with an additional bending stress due to the load offset which is superimposed on the tension stress. To reach the same stress level, as the bending moment increases, the smaller the stress due to direct load has to be. As the bondline thickness increases, there is an increase in the bending stress since the bending moment has increased. Consequently the strength of the joint is reduced. 
The adherend thickness is also important for two reasons [8]. For low strength adherends, an increase in thickness is beneficial because the adherend becomes stronger and less likely to deform plastically. On the other hand, for high strength adherends, a higher thickness can decrease the joint strength due to an increase of the bending moment.

The presence, or otherwise, of a surface treatment is another parameter that can significantly affect the joint strength. Most results in the literature are for mechanical treatments such as shot-blasting [8-10]. In the case of steel, which is the type of substrate studied here, chemical conversion coatings offer several advantages such as high treatment rates, good uniformity, and, particularly, the increased durability in adverse environments where the treatment confers a degree of corrosion protection preventing joint failure through the resultant friable hydrated metal oxide [9-10].

The objective of the present study was to quantify the influence of the adhesive, the adherend, the adherend and adhesive thicknesses, the overlap, the surface treatment and the durability on the lap shear strength by using the Taguchi method [11] and to propose a simple predictive equation that work for any type of situation. A similar study was carried out by the authors in [12] and it was found that the surface treatment had little effect. However, the effect of the durability was not investigated. The main purpose of the present study is to extend the previous study and assess if the previous results are valid when durability is involved. The test speed was also investigated to assess any viscoleastic behaviour. 


\section{Experimental programme}

\subsection{Materials}

Three adhesives were selected: a very ductile polyurethane adhesive (Sikaflex-255 FC); a very brittle two-component epoxy adhesive (Araldite ${ }^{\circledR}$ AV138/HV998 from Huntsman), and an intermediate two-component epoxy adhesive (Araldite ${ }^{\circledR} 2015$ from Huntsman). The adhesives were tested in pure shear according to the thick adherend shear test (ISO 11003-2). The specimens were tested in an MTS servohydraulic machine 312.31 at a crosshead speed of $0.5 \mathrm{~mm} / \mathrm{min}$. Three specimens were tested for each adhesive. The shear mechanical properties of the adhesives used are shown in Table 1. The yield strength was calculated for a plastic deformation of $0.2 \%$ in the case of AV138/HV998. For the more ductile adhesives the yield strength was considered to be equal to the shear strength. To quantify the type of adhesive, the toughness was used by measuring the critical strain energy release rate in mode I $\left(G_{\mathrm{Ic}}\right)$ with the double cantilever beam specimen (ASTM D3433-99). The specimens were tensile tested in an MTS servo-hydraulic machine 312.31 at a crosshead speed of 1 $\mathrm{mm} / \mathrm{min}$. Three specimens were tested for each adhesive. The results are presented in Table 2.

The adherends selected were a low strength steel (DIN St33) with $\sigma_{y s}=184 \mathrm{MPa}$ and a high strength steel (DIN C65 heat treated) with $\sigma_{y s}=1260 \mathrm{MPa}$.

\subsection{Joint geometry}

The single lap joints (SLJ) had an overlap of 12.5, 25 or $50 \mathrm{~mm}$ and a width of 25 mm; see geometry in Figure 1. The adherend thickness was 1, 2 or $3 \mathrm{~mm}$. The SLJs were manufactured individually in a mould and the adhesive thickness was controlled by packing shims. Three values of adhesive thickness were used: 0.5, 1 and $2 \mathrm{~mm}$. 


\subsection{Surface treatment}

\subsubsection{Mechanical treatment $(P)$}

The bonding area was initially degreased with acetone, abraded with a \#180 SiC sandpaper and again cleaned with acetone before the application of the adhesive.

\subsubsection{Chemical conversion coating (A1)}

In all cases, process chemicals used (Gardoclean S5174, Gardobond 901, Gardolene D 6800, Gardolene V6513 and Gardobond R2604) were from Chemetall Ltd (Milton Keynes, UK). Mild steel coupons were first spray cleaned with degreaser Gardoclean $\mathrm{S} 5174$, a proprietary process, at a concentration of $30 \mathrm{~g} \cdot 1^{-1}$ at $50^{\circ} \mathrm{C}$ for 2 minutes. This was followed by a cold water rinse. Coupons were then sprayed at $70^{\circ} \mathrm{C}$, for 30 seconds with Gardobond 901 to produce an amorphous phosphate coating. A nominal coating weight of approximately $0.4 \mathrm{~g} \cdot \mathrm{m}^{-2}$ was produced. A further cold water rinse was carried out. A second treatment with Gardolene D 6800 was then carried out. This is a liquid, acidic, chromium-free, reactive final seal for phosphate-based conversion coatings, applied by immersion. Gardolene D6800 was applied from solution at a concentration of $1.6 \mathrm{~g} \cdot \mathrm{l}^{-1}$ in demineralised water at $\mathrm{pH} 4.2-4.8$ for 30 seconds. Gardolene D 6800 improves the corrosion resistance as well as adhesion of conversion coated metal surfaces that are subsequently coated with conventional organic coatings. Coupons were then air blown and oven dried.

The hard steel was treated as above but was pickled in $16 \% \mathrm{HCl}$ for 15 minutes followed by rubbing with a very fine grade wire wool to deoxidise and to desmut prior to Gardoclean S5174 application. 


\subsubsection{Chemical conversion coating (A2)}

The cleaning and pickling stages detailed above for treatment A1 were used. Following these, conditioning was carried out in Gardolene V6513, a titanium phosphate refiner, applied at a concentration of $0.4 \mathrm{~g} \cdot \mathrm{l}^{-1}$ in demineralised water for 30 seconds. Then this immersion was carried in Gardobond R2604, a trication zinc phosphate, at $53^{\circ} \mathrm{C}$ for 3 minutes. This produces a film of nominal coating weight 2.9 $\mathrm{g} \cdot \mathrm{m}^{-2}$. Panels were then cold water rinsed, air dried and oven dried, as in treatment A1.

\subsection{Ageing conditions}

The joints were subjected to $50^{\circ} \mathrm{C}$ and a relative humidity $(\mathrm{RH})$ of $80 \%$ for 0,1 and 4 weeks. A Weiss Technik chamber SB 500 was used.

\subsection{Test conditions}

The specimens were tested in an MTS servo-hydraulic machine 312.31 with a load cell of $250 \mathrm{kN}$. The test speed was 1,10 or $100 \mathrm{~mm} / \mathrm{min}$ and $25 \%$ of the maximum load cell capacity was used for test recording. Three specimens were tested for each case. Tab ends were used to improve alignment, as shown in Figure 1.

\subsection{Taguchi matrix}

The Taguchi method was used to design the experiments. The Taguchi array contains eight factors, or variables, corresponding to the adherend yield strength, the adherend thickness, the adhesive thickness, the overlap, the adhesive toughness, the test speed, the surface treatment and the durability. If all the possible test combinations were to 
be tested, the number of tests would be 4374 which is impractical in terms of time and cost. The use of pre-defined orthogonal arrays on which the Taguchi method is based reduces the number of tests and permits to quantify the interactions between the variables considered [14].

The $\mathrm{L}_{18}\left(2^{1} \times 3^{7}\right)$ array was selected [15] (see Table 3$)$. It contains 18 rows corresponding to the number of tests, one column with two levels (adherend yield strength) and 7 columns with 3 levels. The first column was assigned to the adherend yield strength $\left(\sigma_{y s}\right)$, the second to the overlap $(l)$, the third to the adherend thickness $\left(t_{s}\right)$, the fourth to the adhesive thickness $\left(t_{a}\right)$, the fifth to the adhesive toughness $\left(G_{\mathrm{Ic}}\right)$, the sixth to the surface treatment $\left(S_{T}\right)$, the seventh to the durability parameter $(A)$ and the eighth to the test speed $(V)$. The response studied was the failure load in the lap shear tests. Interactions between three-level columns are distributed more or less uniformly to all other three-level columns, which permits investigation of main effects. Thus, it is a highly recommended array for reducing the number of experiments [14]. It is, however, possible to assess the interaction between the first (adherend yield strength) and second column (overlap) which was done here.

The influence of each variable and the interaction was assessed by the average response and the analysis of variance (ANOVA). The statistical software Statview ${ }^{\circledR}$ (SAS Institute, Inc., Cary, NC, USA) was used.

\subsection{Surface analysis}

Surface analysis was carried out to identify the changes introduced to the steel substrate by the different pretreatments. Scanning electron microscopy (SEM) and white light interferometry (WLI) were used to study the surface topography whilst Auger electron spectroscopy (AES) was used to determine surface chemistry. 


\subsubsection{White light interferometry (WLI)}

WLI was carried out using a Zygo NearView 5000 interferometer. Several areas on each sample were scanned using a raster width of 520 by $690 \mu \mathrm{m}$.

\subsubsection{Scanning electron microscopy (SEM)}

SEM was conducted using a Leo $1530 \mathrm{VP}$ instrument using a primary beam energy of $10 \times 10^{3} \mathrm{eV}$ and a current of approximately $200 \times 10^{-12} \mathrm{~A}$.

\subsubsection{Auger electron spectroscopy (AES)}

A Joel JAMP 7100 AES spectrometer was used. The primary beam energy was $10 \times 10^{3} \mathrm{eV}$ with a current of $0.7 \times 10^{-6} \mathrm{~A}$. Compositions were determined using experimentally derived relative sensitivity factors based upon $\mathrm{ZrO}_{2}$ and $\mathrm{P}_{2} \mathrm{O}_{5}$ reference materials. In each case, two areas approximately $1 \mathrm{~cm}$ apart were analyzed with an analysis area of $100 \mu \mathrm{m}$ across.

\section{Results}

\subsection{Surface analysis}

\subsubsection{White light interferometry (WLI)}

WLI images are given in Figure 2 for mild steel and in Figure 3 for high strength steel. A summary of roughness values from the aforementioned WLI data are given in Table 4 in two different areas on each surface. The generally rougher, crystalline 
surface texture introduced by A2 is confirmed by this analysis. The grooves from the sandpaper are clearly visible in Figure 3a) and Figure 4a). For treatments A1 and A2, the mild steel surface is more irregular than that of the hard steel and rougher.

\subsubsection{Scanning electron microscopy (SEM)}

SEM images were obtained at both low and high magnifications on all surfaces. The low magnification images were used to determine the uniformity of treatments, in terms of area coverage, whilst the high-resolution images characterized the microrough features present. SEM images are presented in Figures 4 to 6.

Small sub-micrometer sized nodules were apparent, especially at high magnification, for the A1 process, see Figure 4. Such features might be responsible for the formation of an interphase with a subsequently applied adhesive. Many workers have identified the presence of an interphase as contributing towards good adhesion with metallic adherends. However, most A1 treated joints failed with an apparent interfacial failure.

The surface topography of the A2 treated substrates was highly crystalline, see Figure 5. The A2 treated joints gave an apparent interfacial failure, especially for adhesives AV 138 and 2015 and a mixed failure (interfacial and cohesive) for adhesive Sikaflex-255.

As indicated by SEM images in Figure 6, SEM indicated that the sandpaper treatment provided irregular scratches on a macro-rough scale. Good wettability was observed with triply-distilled water indicating that the adhesive would be expected to spread 
well on such a relatively high-energy surface. Adherends prepared with sandpaper gave a cohesive failure for most of the cases.

\subsubsection{Auger electron spectroscopy (AES)}

In Table 5, data is given from one area only but there was very little area-to-area variation. The abraded material comprises carbon/calcium contaminated iron oxide with both steels. The treated surfaces have lower carbon levels and the presence of $\mathrm{Zr}$, $\mathrm{P}$ and $\mathrm{Zn}$ from the conversion coating process. Note that these surfaces have relatively low carbon levels. The precise chemistry of the conversion coating solutions were not disclosed but it is possible that some of the carbon present might contain surface functionalisation suitable for reaction with subsequently applied adhesives or other organic coatings.

\subsection{Lap shear strength}

The experimental failure loads and the mode of failure of the SLJs are shown in Table 3. The failure load predicted using the simple design methodology proposed by Adams et al. [2] (see Figure 7) is also given in Table 3. The load corresponding to the total plastic deformation of the adhesive is given as:

$F_{\mathrm{a}}=\tau_{y} \cdot w \cdot l$

where $F_{\mathrm{a}}$ is the failure load of the adhesive, $\tau_{y}$ is the shear yield strength of the adhesive, $w$ is the joint width and $l$ is the overlap length. The direct tensile stress $\left(\sigma_{t}\right)$ acting in the adherend due to the applied load $F$ is

$\sigma_{t}=F /\left(w \cdot t_{s}\right)$ 
where $t_{s}$ is the adherend thickness. The stress at the inner adherend surface $\left(\sigma_{s}\right)$ due to the bending moment $M$ is

$$
\sigma_{s}=6 M /\left(w \cdot t_{s}^{2}\right)
$$

where $M=k \cdot F \cdot t_{s} / 2$, according to Goland and Reissner [16]. The variable $k$ is the bending moment factor which decreases (from unity) as the lap rotates under load. The stress acting in the adherend is the sum of the direct stress and the bending stress. Thus, the maximum load which can be carried which just creates adherend yield $\left(F_{\mathrm{s}}\right)$ is:

$$
F_{s}=\sigma_{y s} \cdot w \cdot t_{s} /(1+3 k)
$$

where $\sigma_{y s}$ is the yield strength of the adherend. For low loads and short overlaps, $k$ is approximately 1 . Therefore, for such a case,

$$
F_{s}=\sigma_{y s} \cdot w \cdot t_{s} / 4
$$

However, for joints which are long compared to the adherend thickness, such that $l / t_{s} \geq 20$, the value of $k$ decreases and it is assumed here that it tends to zero. In this case, the whole cross section yields and:

$$
F_{\mathrm{s}}=\sigma_{y s} \cdot w \cdot t_{s}
$$

The methodology proposed by Adams et al. [2] works reasonably well when there is yielding of the adherend. The adherend yielding appears clearly in the loaddisplacement curves presented in Figure 8 for test $n^{\circ} 4$ and 7 and is in accordance with Equation 7. Figure 9 shows that the experimental points corresponding to mild steel compare reasonably well with the three curves corresponding to the predictions for $t_{s}=1,2$ and $3 \mathrm{~mm}$ using Equations 6 and 7. The predictions are slightly lower than the experiments because the initial yielding of the steel was used, ignoring the strain hardening of the steel. The points corresponding to tests $n^{\circ} 3$ and 5 have not 
been included because there was failure of the joint before plastic yielding of the adherends.

When the adherends remain in the elastic range, the methodology proposed by Adams et al. [2] may not give satisfactory results (see Figure 10). If the adhesive is very ductile (adhesives 2015 and Sikaflex-255), Equation 2 gives a good prediction. But for brittle adhesives, like adhesive AV 138 and long overlaps, the methodology is not applicable. For this case, the Volkersen's model [17] was used and the failure occurs when the maximum shear stress at the ends of the overlap exceeds the shear strength of the adhesive. The following equation was used:

$P=\tau_{r} \frac{2 b l \sinh (\lambda l)}{\lambda l[1+\cosh (\lambda l)]}$

where

$\lambda^{2}=\frac{G}{t_{\mathrm{a}}}\left(\frac{2}{E t_{s}}\right)$

$t_{\mathrm{a}}$ is the adhesive thickness, $G$ the adhesive shear modulus and $E$ the adherend Young's modulus. This failure criterion works well when the adhesive is brittle, the steel is elastic and the failure is cohesive as in test $n^{\circ} 15$. However, when the failure is adhesive (tests $n^{\circ} 3,5,10$ and 13), the experimental joint strength is much lower than the prediction. The load/displacement curves presented in Figure $\mathbf{1 1}$ are for tests $\mathrm{n}^{\mathbf{o}}$ 17 (AV138) and 18 (Sikaflex-255). In both cases the steel is elastic. The nonlinear behavior observed for test $n^{\circ} 18$ is due to the adhesive deformation. Whereas the adhesive strength of the epoxy (AV138) is more than three times the strength of the polyurethane (Sikaflex-255), the strength of the adhesives in a joint is similar and the polyurethane adhesive has the advantage of being highly deformable. 
Figure 12 presents typical failure surfaces of joints that failed cohesively in the middle of the adhesive (Figure 12a), cohesively in the adhesive but close to the interface (Figure 12b) and adhesively (Figure 12c).

\subsection{Statistical analysis}

\subsubsection{Analysis of variance}

The analysis of variance (ANOVA) (see Table 6) of the experimental results gives the relative importance of all the variables. The main factors influencing the failure load are the overlap (46\%), the adhesive thickness (19\%) and the adherend thickness $(18 \%)$. The other factors are also significant in statistical terms but to a lesser degree being the sum of their contribution of approximately $17 \%$. This result shows that the joint geometry is actually more important than the type of adhesive. Surprisingly, the surface treatment and the durability have very little influence. When compared with our previous study [12], the influence of the overlap is this time much more important (20\% in [12] against $40 \%$ in the present study). This can be explained by the fact that the adhesives used here are more ductile than those used in [12] and therefore make more use of the overlap. Another important difference with our previous results [12] is the effect of the adherend yield strength $(19.7 \%$ in [12] against 3.8 in the present study). This might be due to the fact that in the present study a high number of cases for the high strength steel (cases 10,13 and 16 in Table 3) had an adhesive failure giving a lower failure load than expected. This might have decreased the effect of the adherend yield strength.

The main effect of the adherend yield strength is shown in Figure 13. As expected, the failure load increases with the adherend yield strength. As the adherend plastic 
deformation decreases, the adhesive can develop its full shear strength capacity and give a higher joint strength.

Figure 14 shows that the joint strength increases almost linearly with overlap. The overlap is the factor that has the biggest impact in the joint strength. This might be due to the fact that two ductile adhesives were used in the present study, which allow to use the whole overlap even for long overlaps.

The Taguchi array used here permits to evaluate the interaction between the adherend yield strength and the overlap, as shown in Figure 15. The graph failure load vs. overlap is nearly linear for the two types of adherend but the two lines are not parallel. The overlap effect increases as the adherend gets stronger. When the adherend is elastic, the adhesive can develop its full shear strength capacity and make use of the whole overlap. da Silva et al. [18] have shown this effect with more clarity for three different types of steels of increasing yield strength. They have also shown that there is interaction between adherend and adhesive and between adhesive and overlap but their percentage of contribution were low.

The main effect of the adherend thickness is presented in Figure 16. The increase is almost linear. This can be explained by the plasticity of the steel. As the adherend thickness increases, the resistant area of the steel increases and the adherend becomes stronger giving a chance to the adhesive to develop its full shear strength capacity. This, of course, is especially valid for the low strength steel because the high strength steel does not deform plastically for any thickness.

The influence of the adhesive thickness, presented in Figure 17 confirms previous experimental results $[3,4]$.

The effect of the adhesive toughness on the failure load is shown in Figure 18. The adhesive toughness increases the joint failure load up to $500 \mathrm{~N} / \mathrm{m}$ and then there is a 
decrease for the polyurethane adhesive which a fracture toughness of $2900 \mathrm{~N} / \mathrm{m}$. There seems therefore to be a peak corresponding to the best comprise between the adhesive toughness and the adhesive strength. The present Taguchi array is limited in terms of interactions assessment. However, da Silva et al. [18] have shown that for low strength steel, the failure load is independent of the adhesive; whereas for high strength steel, the failure load increases as the adhesive gets tougher.

Figure 19 gives the effect of the surface preparation. Surprisingly, the surface preparation has little effect on the joint strength. Even though the surface treatment results are not conclusive, Figure 19 seems to indicate that treatments $\mathrm{A} 1$ and $\mathrm{P}$ are better than A2. This confirms previous results from reference [10, 13] with similar surface treatments.

The effect of the ageing is shown in Figure 20. The joint strength seems to be independent of the ageing conditions, at least for the conditions and times used here. The test speed effect is also negligible (see Figure 21). This result is not surprising since all adhesives were used well below (case of epoxy adhesives 2015 and AV138) and well above (case of the polyurethane) their glass transition temperature where the viscoelastic effects are not substantial.

\subsubsection{Linear regression}

Two linear regressions were determined $\left(F_{L}{ }^{1}\right.$ and $\left.F_{L}{ }^{2}\right)$. In the first linear regression, all the variables were used:

$$
\begin{aligned}
& F_{L}=M+\left(\overline{\sigma_{y s i}}-M\right)+\left(\overline{l_{i}}-M\right)+\left(\overline{t_{s i}}-M\right)+ \\
& +\left(\overline{t_{a i}}-M\right)+\left(\overline{G_{I c i}}-M\right)+\left(\overline{S_{T i}}-M\right)+\left(\overline{A_{i}}-M\right)+\left(\overline{V_{i}}-M\right)
\end{aligned}
$$


where $F_{L}$ is the failure load prediction, $M$ is the average failure load, $\overline{\sigma_{y s i}}$ is the adherend yield strength at level $i, \overline{t_{s i}}$ is the adherend thickness at level $i, \overline{t_{a i}}$ is the adhesive thickness at level $i, \bar{l}_{i}$ is the overlap at level $i, \overline{G_{\text {Ic } i}}$ is the adhesive toughness at level $i, \overline{S_{T i}}$ is the surface treatment at level $i, \overline{A_{i}}$ is the durability al level $i$ and $\bar{V}_{i}$ is the test speed at level $i$. The values of $\overline{\sigma_{y s i}}, \bar{l}_{i}, \overline{t_{s i}}, \overline{t_{a i}}, \overline{G_{\text {Ic }}}, \overline{A_{i}}$ and $\bar{V}_{i}$ can be determined by the equation that best fits the data presented in Figures 13, 15, 16, 17, 19 and 20 respectively. The non quantitative variable surface treatment had to be treated with two dummy variables $M 1$ and $M 2$. Surface treatment $\mathrm{P}$ corresponds to $M 1$ $=0$ and $M 2=1$, surface treatment $\mathrm{A} 1$ to $M 1=1$ and $M 2=0$ and surface treatment A2 to $M 1=1$ and $M 2=1$. The resulting equation is:

$$
\begin{aligned}
& F_{L}{ }^{1}=1,535 \times \sigma_{y s}+166,442 \times l+2156,871 \times t_{s}-2148,964 \times t_{a}- \\
& -0,490 \times G_{I c}-636,525 \times M 1-813,590 \times M 2+87,095 \times A+5,884 \times V
\end{aligned}
$$

where $\sigma_{y s}$ is the adherend yield strength in $\mathrm{MPa}, t_{s}$ is the adherend thickness in $\mathrm{mm}, t_{a}$ is the adhesive thickness in $\mathrm{mm}, l$ is the overlap in $\mathrm{mm}, G_{I c}$ is the critical strain energy release rate, $M 1$ and $M 2$ are the dummy variables defined above, $A$ is the ageing in weeks and $V$ is the test speed in $\mathrm{mm} / \mathrm{min}$. The square of coeffecient of correlation $\left(R^{2}\right)$ was found to be 0.977 .

The second linear regression was determined using the stepwise regression technique where in each step the most important variables (highest contribution) are tried in order to maximize the value of $R^{2}$. The regression was obtained in five steps and the following relation was obtained:

$$
F_{L}{ }^{2}=1,446 \times \sigma_{y s}+162,171 \times l+2050,100 \times t_{s}-2255,735 \times t_{a}-0,52390 \times G_{I c}
$$

A value of 0.973 was obtained for $R^{2}$, which is comparable to the first linear regression. 
The two linear regressions defined above (Equations 10 and 11) were used to predict the failure load from tests available in the literature. Table 7 shows that the predicted failure loads compare generally well with the experimental failure loads. This result shows that a statistical analysis can be an alternative method for the prediction of joint strength. The two equations give similar results and it is therefore advised to use Equation 11 for its simplicity.

The results obtained in the present study were also used to reconfirm the validity of the linear regression obtained in [12] and to conclude about the most appropriate of the two linear regressions. The linear regression obtained in [12] is:

$$
F_{L}=-6.625+0.005 \sigma_{y s}+5.225 t_{s}-7.359 t_{a}+0.161 l+0.519 U_{T}
$$

Note that in [12] the effect of the adhesive was taken as the area under the stressstrain curve $\left(U_{T}\right)$. The $U_{T}$ is just available for adhesives AV138/HV998 and 2015. Table 8 shows that the failure prediction of [12] is valid and give similar results to those obtained with the present linear regression (see Equation (11) and Table 3), except for case 2. This is because Equation (12) was obtained for an adhesive thickness between 0.1 and $0.5 \mathrm{~mm}$ whereas case 2 has an adhesive thickness of $1 \mathrm{~mm}$. This is an example where an extrapolation of the linear regression does not give satisfactory results. Therefore, due to its wider range of application, the linear regression of the present study (Equation (11)) is recommended. Moreover, the type of adhesive is better represented using $G_{I C}$ than $U_{T}$.

\section{Conclusions}

SLJs made of carbon steel were studied. The effects of adherend yield strength, adherend thickness, adhesive thickness, overlap, adhesive toughness, surface 
treatment, durability and test speed on the lap shear strength were investigated using the Taguchi method. The experimental results were statistically treated to give a failure load predictive equation. For the conditions tested here, the following conclusions can be drawn:

1. The lap shear strength increases with the overlap ( $45.5 \%$ contribution).

2. The lap shear strength decreases as the adhesive thickness increases $(18.9 \%$ contribution).

3. The lap shear strength increases as the adherend thickness decreases $(18.4 \%$ contribution).

4. The lap shear strength increases with the adherend yield strength $(3.8 \%$ contribution).

5. The lap shear strength increases with the adhesive toughness from $346 \mathrm{~N} / \mathrm{m}$ to 526 $\mathrm{N} / \mathrm{m}$ and then decreases to $2902 \mathrm{~N} / \mathrm{m}$ (5.5\% contribution).

6. The effect of the surface treatment, durability and test speed are negligible.

7. The Taguchi method is a valid technique for lap shear strength prediction.

\section{References}

[1] Hart-Smith LJ. NASA Contract Report, NASA CR-112235, 1973.

[2] Adams RD, Comyn J, Wake WC. Structural adhesive joints in engineering, 2nd ed. London: Chapman \& Hall, 1997.

[3] Adams RD, Peppiatt NA. J Strain Anal 1974; 9: 185.

[4] da Silva LFM, Rodrigues TNSS, Figueiredo MAV, de Moura MFSF, Chousal JAG. J Adhesion 2006; 82: 1091.

[5] Crocombe AD. Int J Adhes Adhes 1989; 9: 145. 
[6] Gleich DM, van Tooren MJL, Beukers A. J Adhesion Sci Technol 2001; 15: 1091.

[7] Grant LDR, Adams RD, da Silva LFM. Int J Adhes Adhes 2008, doi:10.1016/j.ijadhadh.2008.09.001.

[8] Gledhill RA, Shaw SJ, Tod DA, Int J Adhes Adhes 1990; 10: 192.

[9] Critchlow GW, Webb PW, Tremlett CJ, Brown K. Int J Adhes Adhes 2000; 20: 113.

[10] Gan LM, Ong HWK, Tan TL. J Adhesion 1984; 16: 233.

[11] Taguchi G, Chowdhury S, Taguchi S. Robust engineering, New York: McGraw-Hill, 2000.

[12] da Silva LFM, Critchlow GW, Figueiredo MAV, J Adhesion Sci Technol 2008; $22(13): 1477-1494$

[13] da Silva LFM, Adams RD, Gibbs M. Int J Adhes Adhes 2004; 24, 69.

[14] Ross PJ. Taguchi Techniques for quality engineering loss function, orthogonal experiments, parameter and tolerance design, New York: McGraw-Hill, 1991.

[15] Taguchi G, Konishi S. Orthogonal arrays and linear graphs, Dearborn, MI: ASI Press, 1987.

[16] Goland M, Reissner E. J Appl Mech 1944; 66: A17.

[17] Volkersen O. Luftfahrtforschung 1938; 15: 41.

[18] da Silva LFM, Ramos JE, Figueiredo MV, Strohaecker TR. J Adhesion and Interface 2006; 7, 1.

[19] Fowlkes WY, Creveling CM. Engineering methods for robust product design, Reading, MA: Addison-Wesley, 1995. 
Table 1 Adhesive shear properties using the thick adherend shear test method ISO 11003-2 (three specimens tested for each temperature).

\begin{tabular}{|c|c|c|c|}
\hline & $\begin{array}{c}\text { Araldite }^{\circledR} \\
\text { AV138M / } \\
\text { HV998 }\end{array}$ & $\begin{array}{l}\text { Araldite }^{\circledR} \\
2015\end{array}$ & $\begin{array}{c}\text { Sikaflex-255 } \\
\text { FC }\end{array}$ \\
\hline $\begin{array}{l}\text { Shear modulus } \\
G(\mathrm{MPa})\end{array}$ & $1559 \pm 11$ & $487 \pm 77$ & $1.351 \pm 0.04$ \\
\hline $\begin{array}{l}\text { Shear yield strength } \\
\tau_{\mathrm{ya}}(\mathrm{MPa})\end{array}$ & $25.0 \pm 0.55$ & $17.9 \pm 1.8$ & $8.26 \pm 0.30$ \\
\hline $\begin{array}{l}\text { Shear strength } \\
\tau_{\mathrm{r}}(\mathrm{MPa})\end{array}$ & $30.2 \pm 0.40$ & $17.9 \pm 1.8$ & $8.26 \pm 0.30$ \\
\hline $\begin{array}{l}\text { Shear failure strain } \\
\gamma_{\mathrm{f}}(\%)\end{array}$ & $5.50 \pm 0.44$ & $43.9 \pm 3.4$ & $330 \pm 27$ \\
\hline
\end{tabular}

Table 2 Adhesive critical strain energy release rate in mode I $\left(G_{\text {Ic }}\right)$ measured with the double cantilever beam ASTM D3433-99 (three specimens tested for each temperature).

\begin{tabular}{|l|c|c|c|}
\hline & $\begin{array}{c}\text { Araldite }^{\circledR} \\
\text { AV138M } / \\
\text { HV998 }\end{array}$ & $\begin{array}{c}\text { Araldite }^{\circledR} \\
2015\end{array}$ & $\begin{array}{c}\text { Sikaflex-255 } \\
\text { FC }\end{array}$ \\
\hline $\begin{array}{l}\text { Critical strain energy release rate } \\
\text { in mode I } \\
G_{\text {Ic }}(\mathrm{N} / \mathrm{m})\end{array}$ & $345.9 \pm 47.8$ & $525.7 \pm 80.8$ & $\begin{array}{c}2901.1 \pm \\
121.9\end{array}$ \\
\hline
\end{tabular}


Table 3 Experimental plan based on Taguchi orthogonal array $\left(\mathrm{L}_{18}\right)$.

\begin{tabular}{|c|c|c|c|c|c|c|c|c|c|c|c|c|c|}
\hline Test & $\sigma_{y s}$ & $l$ & $t_{s}$ & $t_{a}$ & $G_{\text {Ic }}$ & $S_{T}$ & $A$ & V & & Experim. & $F_{L}$ & Predicted & Error \\
\hline $\mathrm{n}^{\mathrm{o}}$ & {$[\mathrm{MPa}]$} & {$[\mathrm{mm}]$} & {$[\mathrm{mm}$} & {$[\mathrm{mm}]$} & {$[\mathrm{N} / \mathrm{m}]$} & & [sem.] & {$[\mathrm{mm} / \mathrm{min}$.} & {$[\mathrm{kN}]$} & Mode & {$[\mathrm{kN}]$} & Criterion & {$[\%]$} \\
\hline 1 & 184 & 12.5 & 1 & 0.5 & 2902 & $\mathrm{P}$ & 0 & 1 & 2.36 & DP/Coes & 3.31 & \begin{tabular}{|l|}
$\mathrm{DP}$ \\
\end{tabular} & 40.3 \\
\hline 2 & 184 & 12.5 & 2 & 1 & 526 & $\mathrm{~A} 1$ & 1 & 10 & 5.42 & $\mathrm{DP} / \mathrm{Int}$ & 4.46 & DP & 17. \\
\hline 3 & 184 & 12.5 & 3 & 2 & 346 & A2 & 4 & 100 & 3.10 & Ades & & & \\
\hline 4 & 184 & 25 & 1 & 0.5 & 526 & A1 & 4 & 100 & 7.02 & DP/Int & 4.60 & DP & 34. \\
\hline 5 & 184 & 25 & 2 & 1 & 346 & A2 & 0 & 1 & 3.05 & Ades & & & \\
\hline 6 & 184 & 25 & 3 & 2 & 2902 & $\mathrm{P}$ & 1 & 10 & 5.19 & DP/Coes & 6.90 & DP & 32 \\
\hline 7 & 184 & 50 & 1 & 1 & 2902 & $\mathrm{~A} 2$ & 1 & 100 & 6.44 & DP/Mist & 4.60 & DP & 28. \\
\hline 8 & 184 & 50 & 2 & 2 & 526 & $\mathrm{P}$ & 4 & 1 & 8.41 & DP/Int & 9.20 & DP & \\
\hline 9 & 184 & 50 & 3 & 0.5 & 346 & $\mathrm{~A} 1$ & 0 & 10 & 12.60 & DP/Int & 12.08 & DP & \\
\hline 10 & 1260 & 12.5 & 1 & 2 & 346 & A1 & 1 & 1 & 1.81 & Ades & & & \\
\hline 11 & 1260 & 12.5 & 2 & 0.5 & 2902 & $\mathrm{~A} 2$ & 4 & 10 & 3.84 & Coes & 2.58 & $\mathrm{CG}$ & 32 \\
\hline 12 & 1260 & 12.5 & 3 & 1 & 526 & $\mathrm{P}$ & 0 & 100 & 6.97 & Mist & 5.60 & $\mathrm{CG}$ & 19 \\
\hline 13 & 1260 & 25 & 1 & 1 & 346 & $\mathrm{P}$ & 4 & 10 & 5.24 & Ades & & & \\
\hline 14 & 1260 & 25 & 2 & 2 & 2902 & A1 & 0 & 100 & 4.48 & Coes & 5.16 & $\mathrm{CG}$ & 15.2 \\
\hline 15 & 1260 & 25 & 3 & 0.5 & 526 & A2 & 1 & 1 & 12.39 & Coes & 11.19 & CG & \\
\hline 16 & 1260 & 50 & 1 & 2 & 526 & A2 & 0 & 10 & 6.12 & Ades & & & \\
\hline 17 & 1260 & 50 & 2 & 0.5 & 346 & $\mathrm{P}$ & 1 & 100 & 13.67 & Int & 11.99 & Volk & 12 \\
\hline 18 & 1260 & 50 & 3 & 1 & 2902 & A1 & 4 & 1 & 11.40 & Coes & 10.33 & $\mathrm{CG}$ & \\
\hline
\end{tabular}

$F_{L}$ - Failure load Coes - Cohesive failure

DP - Plastic deformation of the steel

CG - Global yielding of the adhesive

Volk - Model of Volkersen
Int - Cohesive failure close to the interface

Ades - Adhesive failure

Mist - Mixed failure 
Table 4 Summary of WLI topographical data $-520 \mu \mathrm{m}$ x $690 \mu \mathrm{m}$ scan.

\begin{tabular}{|l|l|l|l|l|l|}
\hline & Treatment & Area & $\begin{array}{l}\text { Area } \\
(\mathrm{nm})\end{array}$ & $\begin{array}{l}\text { Area RMS } \\
(\mathrm{nm})\end{array}$ & $\begin{array}{l}\text { Max range } \\
\mathrm{R}_{\mathrm{z}} \\
(\mathrm{nm})\end{array}$ \\
\hline \multirow{4}{*}{$\begin{array}{l}\text { Low strength } \\
\text { steel }\end{array}$} & $\mathrm{P}$ & $\mathrm{A}$ & 305 & 407 & 3301 \\
\cline { 2 - 6 } & & $\mathrm{B}$ & 241 & 313 & 2910 \\
\cline { 2 - 6 } & $\mathrm{A} 2$ & $\mathrm{~A}$ & 331 & 448 & 3880 \\
\cline { 2 - 6 } & & $\mathrm{B}$ & 288 & 418 & 5215 \\
\cline { 2 - 6 } & $\mathrm{A} 1$ & $\mathrm{~A}$ & 163 & 224 & 1639 \\
\cline { 2 - 6 } & & $\mathrm{B}$ & 204 & 290 & 2299 \\
\hline \multirow{4}{*}{$\begin{array}{l}\text { High strength } \\
\text { steel }\end{array}$} & $\mathrm{P}$ & $\mathrm{A}$ & 203 & 270 & 2218 \\
\cline { 2 - 6 } & & $\mathrm{B}$ & 199 & 262 & 1715 \\
\cline { 2 - 6 } & & $\mathrm{A}$ & 248 & 333 & 2980 \\
\cline { 2 - 6 } & $\mathrm{A} 1$ & $\mathrm{~B}$ & 300 & 375 & 2320 \\
\cline { 2 - 6 } & & $\mathrm{A}$ & 153 & 222 & 2517 \\
\hline
\end{tabular}

Table 5 AES data: surface composition atom\%, excluding $\mathrm{H}$ and $\mathrm{He}$.

\begin{tabular}{|c|c|c|c|c|c|c|c|c|}
\hline Substrate & Treatment & $\mathrm{C}$ & $\mathrm{Ca}$ & $\mathrm{O}$ & $\mathrm{Fe}$ & $\mathrm{Zr}$ & $\mathrm{P}$ & $\mathrm{Zn}$ \\
\hline Hard steel & $\mathrm{P}$ & 51.4 & 3.3 & 28.2 & 17.1 & 0.0 & 0.0 & 0.0 \\
\hline & $\mathrm{A} 1$ & 17.0 & 1.8 & 51.6 & 6.4 & 9.3 & 10.1 & 3.7 \\
\hline & $\mathrm{A} 2$ & 21.6 & 0.0 & 41.9 & 3.1 & 5.6 & 13.8 & 14.1 \\
\hline Mild steel & $\mathrm{P}$ & 36.6 & 4.8 & 36.7 & 22.0 & 0.0 & 0.0 & 0.0 \\
\hline & $\mathrm{A} 1$ & 14.2 & 2.2 & 51.4 & 11.5 & 10.4 & 7.7 & 2.6 \\
\hline & $\mathrm{A} 2$ & 26.2 & 0.0 & 41.2 & 0.0 & 8.1 & 5.6 & 18.9 \\
\hline
\end{tabular}


Table 6 Analysis of variance (ANOVA) results.

\begin{tabular}{|l|c|c|c|c|c|c|}
\hline \multicolumn{1}{|c|}{ Source } & Sum of squares & Degrees of freedom & Mean square & F-value & P-value & $\%$ of contribution \\
\hline$\sigma_{y s}$ & 35831282.2 & 1 & 35831280.0 & 320.6106 & 0.0001 & 3.8 \\
\hline$l$ & 426166569.1 & 2 & 213083300.0 & 1906.6236 & 0.0001 & 45.5 \\
\hline$t_{s}$ & 171951105.5 & 2 & 85975550.0 & 769.2908 & 0.0001 & 18.4 \\
\hline$t_{a}$ & 176921151.3 & 2 & 88460580.0 & 791.5263 & 0.0001 & 18.9 \\
\hline$G_{\text {Ic }}$ & 51724615.9 & 2 & 25862310.0 & 231.4104 & 0.0001 & 5.5 \\
\hline$S T$ & 25921273.1 & 2 & 12960640.0 & 115.9690 & 0.0001 & 2.7 \\
\hline$A$ & 29737429.3 & 2 & 14868710.0 & 133.0420 & 0.0001 & 3.2 \\
\hline$V$ & 3208753.7 & 2 & 1604377.0 & 14.3556 & 0.0001 & 0.3 \\
\hline$\sigma_{y s} * l$ & 8145888.8 & 2 & 4072944.0 & 36.4438 & 0.0001 & 0.8 \\
\hline Residual (error) & 6035013.5 & 54 & 111759.5 & & & 0.8 \\
\hline Total & 935643082.2 & & & & & 100.0 \\
\hline
\end{tabular}


Table 7 Experimental validation of the statistical failure load prediction.

\begin{tabular}{|r|c|c|c|c|c|c|c|c|c|c|c|c|c|}
\hline \multirow{2}{*}{ Case } & $\sigma_{y s}$ & $l$ & $t_{s}$ & $t_{a}$ & $G_{\text {Ic }}$ & $S_{T}$ & $A$ & $V$ & $F_{L}{ }^{\text {Experim. }}$ & $F_{L}{ }^{l}$ & Error 1 & $F_{L}{ }^{2}$ & Error 2 \\
\hline & {$[\mathrm{MPa}]$} & {$[\mathrm{mm}]$} & {$[\mathrm{mm}]$} & {$[\mathrm{mm}]$} & {$[\mathrm{N} / \mathrm{m}]$} & & {$[$ weeks] } & {$[\mathrm{mm} / \mathrm{min}]$.} & {$[\mathrm{kN}]$} & {$[\mathrm{kN}]$} & {$[\%]$} & {$[\mathrm{kN}]$} & {$[\%]$} \\
\hline 1 & 184 & 12.5 & 2 & 0.2 & 450 & $\mathrm{P}$ & 0 & 1 & 6.07 & 5.22 & 14.0 & 5.71 & 6.0 \\
\hline 2 & 184 & 25 & 2 & 0.2 & 450 & $\mathrm{P}$ & 0 & 1 & 9.02 & 7.30 & 19.1 & 7.73 & 14.3 \\
\hline 3 & 184 & 50 & 2 & 0.2 & 450 & $\mathrm{P}$ & 0 & 1 & 12.1 & 11.46 & 5.3 & 11.79 & 2.6 \\
\hline 4 & 419 & 12.5 & 2 & 0.2 & 450 & $\mathrm{P}$ & 0 & 1 & 7.33 & 5.58 & 23.9 & 6.05 & 17.5 \\
\hline 5 & 419 & 25 & 2 & 0.2 & 450 & $\mathrm{P}$ & 0 & 1 & 10.65 & 7.66 & 28.1 & 8.07 & 24.2 \\
\hline 6 & 419 & 50 & 2 & 0.2 & 450 & $\mathrm{P}$ & 0 & 1 & 15.46 & 11.82 & 23.5 & 12.13 & 21.6 \\
\hline 7 & 1078 & 12.5 & 2 & 0.2 & 450 & $\mathrm{P}$ & 0 & 1 & 6.37 & 6.59 & 3.5 & 7.00 & 9.9 \\
\hline 8 & 1078 & 25 & 2 & 0.2 & 450 & $\mathrm{P}$ & 0 & 1 & 11.1 & 8.67 & 21.9 & 9.03 & 18.7 \\
\hline 9 & 1078 & 50 & 2 & 0.2 & 450 & $\mathrm{P}$ & 0 & 1 & 16.88 & 12.83 & 24.0 & 13.08 & 22.5 \\
\hline 10 & 184 & 25 & 1 & 0.2 & 346 & A2 & 0 & 1 & 3.57 & 4.56 & 27.6 & 5.74 & 60.7 \\
\hline 11 & 184 & 50 & 1 & 0.5 & 450 & $\mathrm{P}$ & 0 & 1 & 6.83 & 8.66 & 26.8 & 9.06 & 32.7 \\
\hline 12 & 184 & 12.5 & 1.5 & 0.1 & 346 & A2 & 0 & 1 & 3.58 & 3.77 & 5.3 & 4.96 & 38.6 \\
\hline 13 & 184 & 25 & 1.5 & 0.2 & 450 & $\mathrm{P}$ & 0 & 1 & 8.55 & 6.22 & 27.2 & 6.71 & 21.5 \\
\hline 14 & 184 & 50 & 2 & 0.2 & 346 & A1 & 0 & 1 & 12.08 & 11.69 & 3.2 & 11.84 & 2.0 \\
\hline 15 & 184 & 12.5 & 2 & 0.5 & 450 & A2 & 0 & 1 & 3.47 & 3.94 & 13.5 & 5.03 & 45.0 \\
\hline 16 & 1260 & 50 & 1 & 0.1 & 450 & A2 & 0 & 1 & 6.56 & 10.53 & 60.6 & 11.52 & 75.6 \\
\hline 17 & 1260 & 25 & 1 & 0.5 & 346 & A1 & 0 & 1 & 4.84 & 6.38 & 31.8 & 6.62 & 36.7 \\
\hline 18 & 1260 & 25 & 1.5 & 0.1 & 450 & A1 & 0 & 1 & 16.05 & 8.26 & 48.5 & 8.49 & 47.1 \\
\hline 19 & 1260 & 12.5 & 1.5 & 0.5 & 346 & P & 0 & 1 & 5.95 & 5.20 & 12.6 & 5.62 & 5.6 \\
\hline 20 & 1260 & 50 & 2 & 0.1 & 346 & P & 0 & 1 & 15.37 & 13.38 & 13.0 & 13.62 & 11.4 \\
\hline 21 & 1260 & 12.5 & 2 & 0.2 & 450 & A1 & 0 & 1 & 11.91 & 7.05 & 40.8 & 7.26 & 39.0 \\
\hline
\end{tabular}

Cases 1 to 9, see ref [19]

Cases 10 to 21, see ref [12]

Table 8 Validation of the statistical failure load prediction of [12] using the present experimental results.

\begin{tabular}{|c|c|c|c|c|c|c|c|c|c|}
\hline $\begin{array}{l}\text { Case } \\
\text { (see } \\
\text { Table 3) }\end{array}$ & $\sigma_{y s}$ & $t_{\mathrm{s}}$ & $t_{\mathrm{a}}$ & $l$ & $\overline{U_{T}}$ & $S_{T}$ & $F_{L}^{\text {Experim. }}$ & $\begin{array}{l}F_{L} \\
\text { (using } \\
\text { Eq. 12) }\end{array}$ & Error \\
\hline & {$[\mathrm{MPa}]$} & {$[\mathrm{mm}]$} & {$[\mathrm{mm}]$} & {$[\mathrm{mm}]$} & {$[\mathrm{MPa}]$} & & {$[\mathrm{kN}]$} & {$[\mathrm{kN}]$} & {$[\%]$} \\
\hline 9 & 184 & 3 & 0.5 & 50 & 0.49 & A1 & 12.6 & 10.43 & 17.18 \\
\hline 17 & 1260 & 2 & 0.5 & 50 & 0.49 & $\mathrm{P}$ & 13.67 & 12.03 & 11.96 \\
\hline 2 & 184 & 2 & 1 & 12.5 & 1 & A1 & 5.42 & -1.79 & 132.96 \\
\hline 15 & 1260 & 3 & 0.5 & 25 & 1 & A2 & 12.39 & 11.78 & 4.91 \\
\hline
\end{tabular}




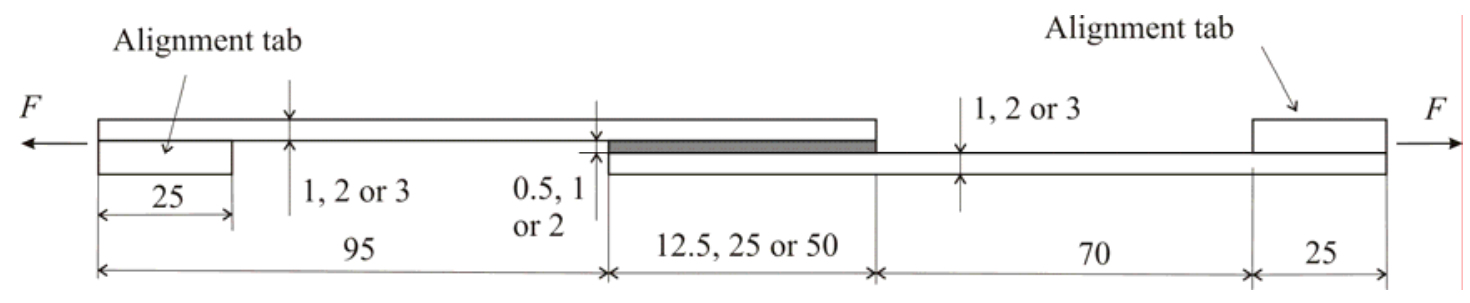

Figure 1 Single lap joints geometry (not to scale, dimensions in $\mathrm{mm}$ ). 

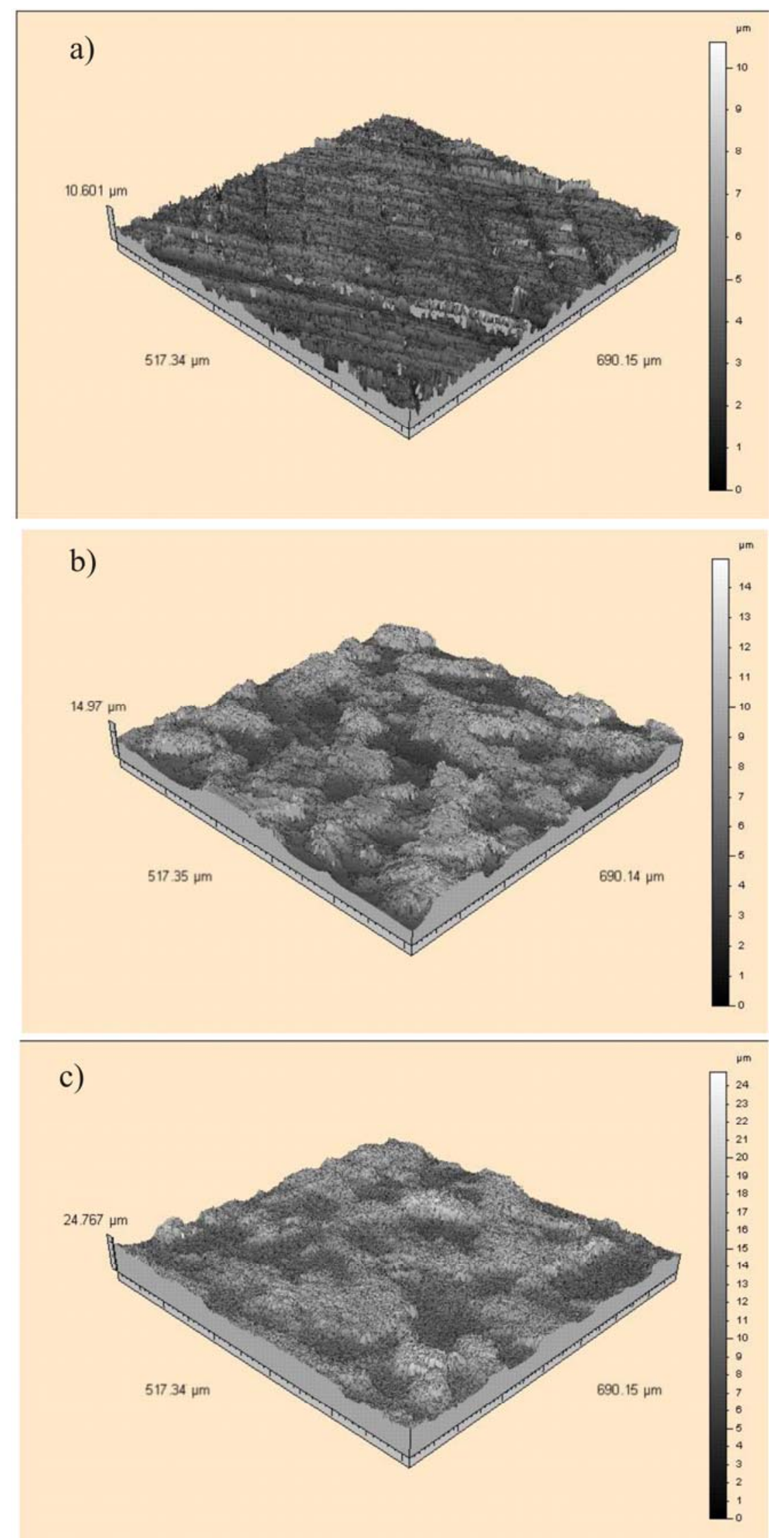

Figure 2 WLI images of low strength steel; a) from treatment P; b) from treatment $\mathrm{A} 1$; c) from treatment $\mathrm{A} 2$. 

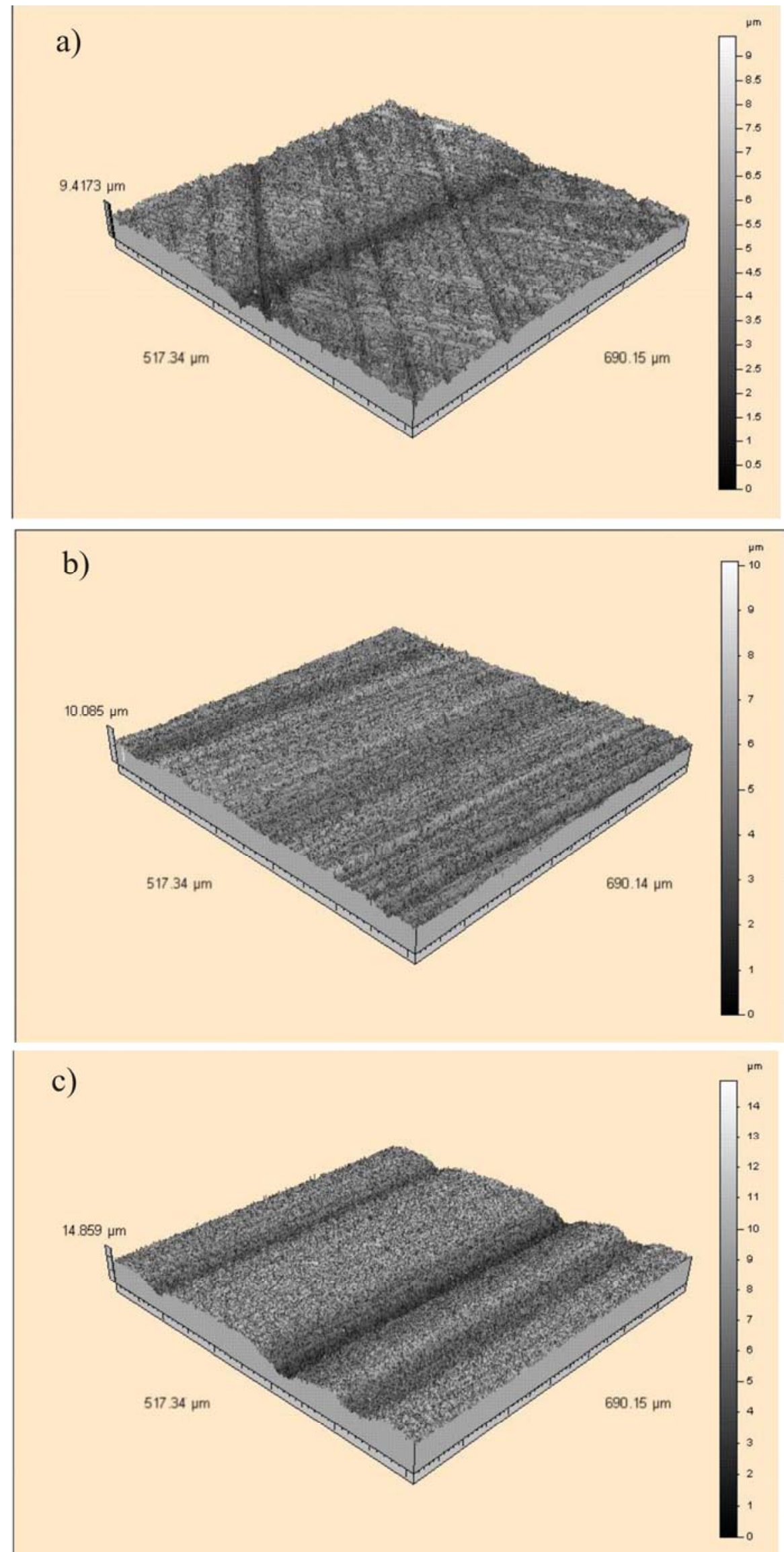

Figure 3 WLI images of high strength steel; a) from treatment P; b) from treatment $\mathrm{A} 1$; c) from treatment $\mathrm{A} 2$. 


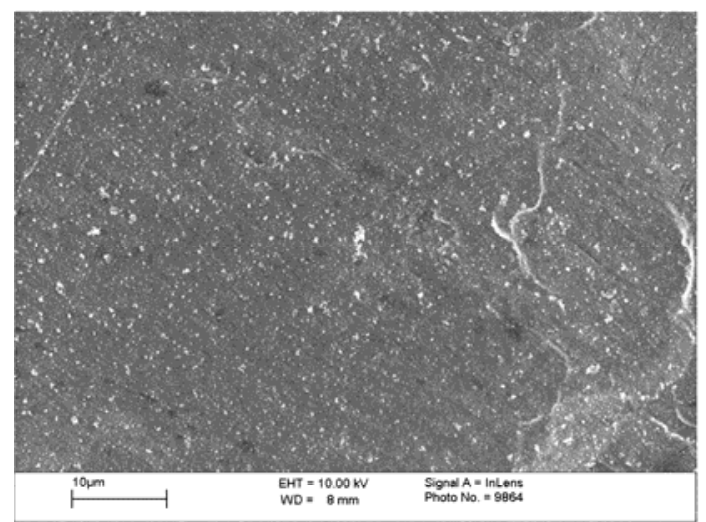

Mild steel, LM

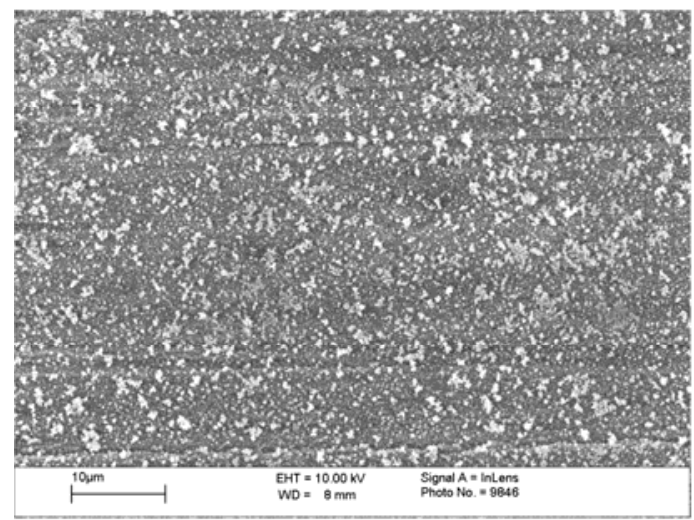

High strength steel, LM

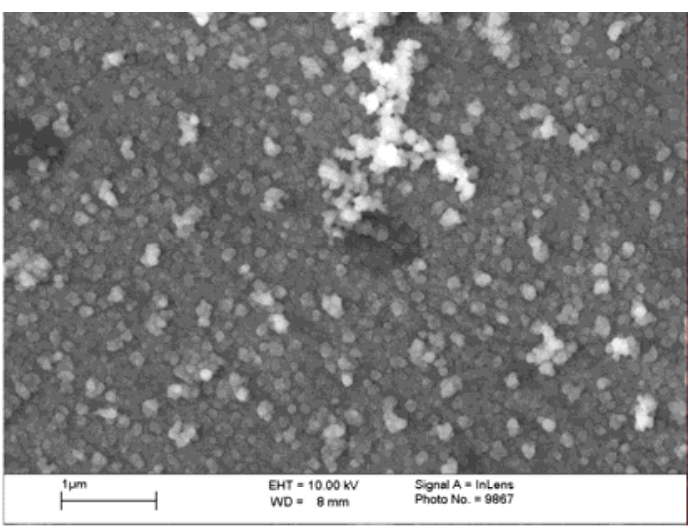

Mild steel, HM

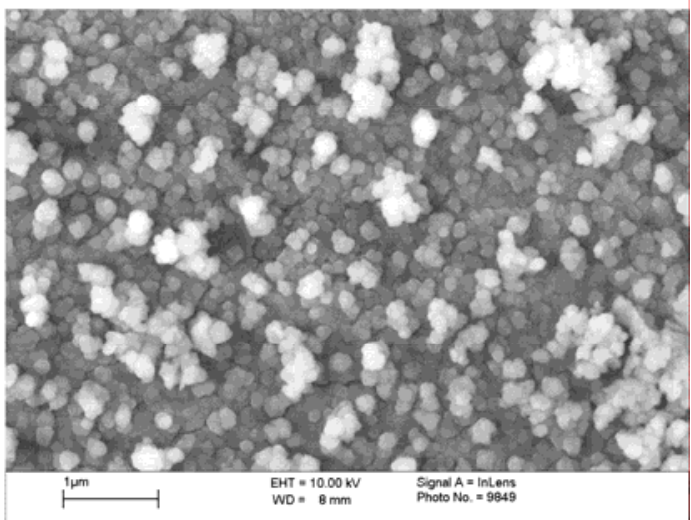

High strength steel, HM

Figure 4 SEM images for A1 treatment of different steels (LM low magnification and HM high magnification). 


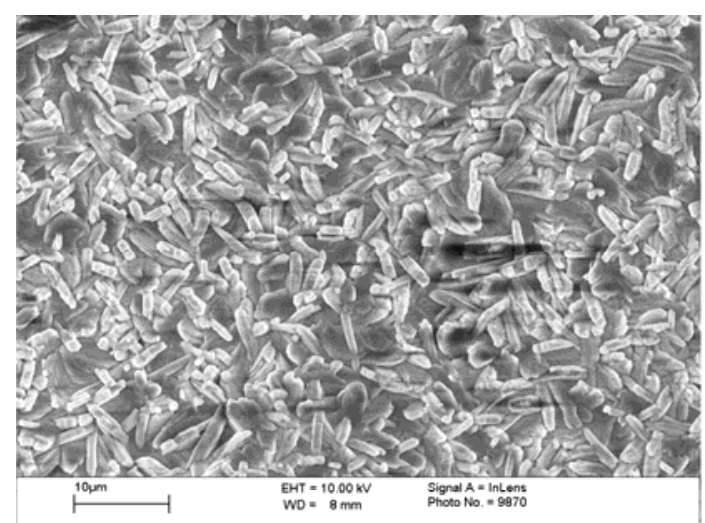

Mild steel, LM

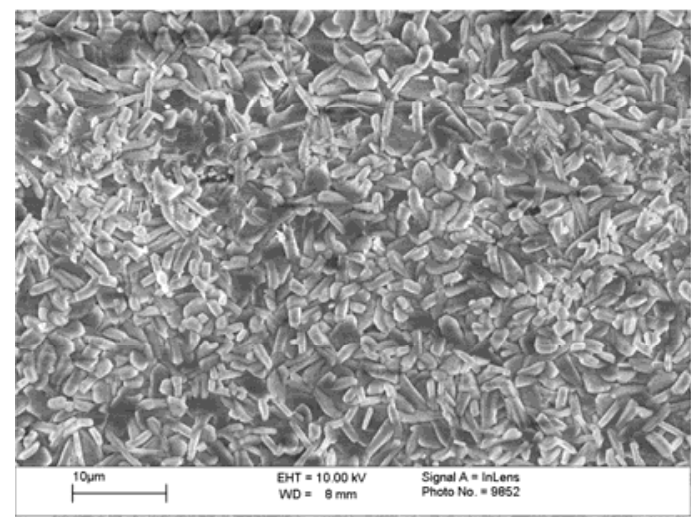

High strength steel, LM

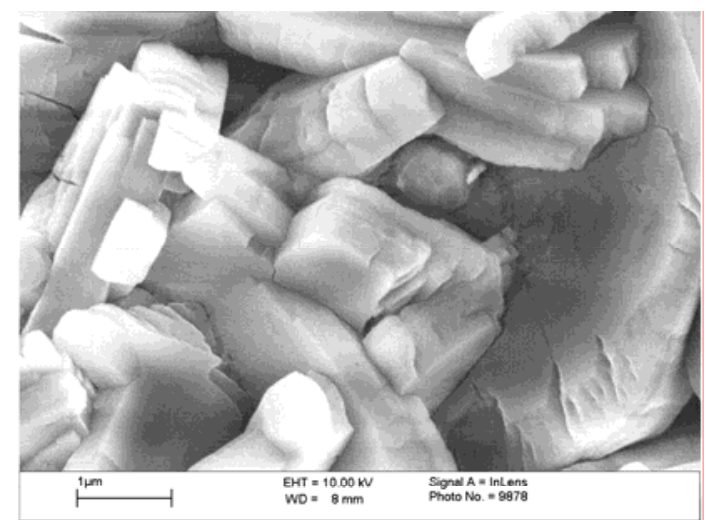

Mild steel, HM

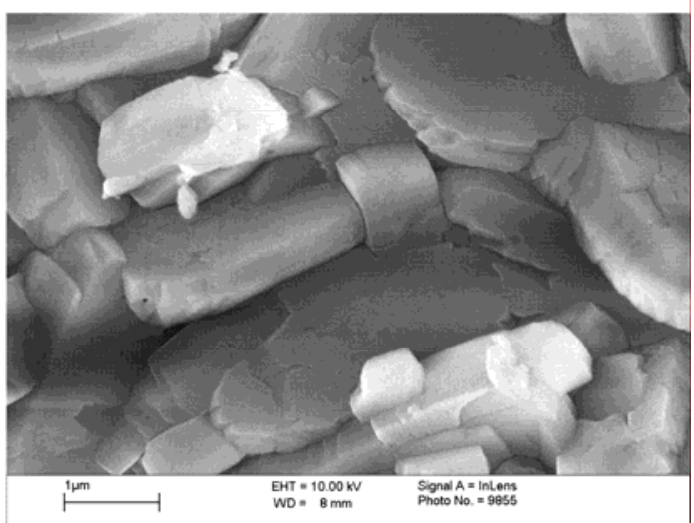

High strength steel, HM

Figure 5 SEM images for A2 treatment of different steels (LM low magnification and $\mathrm{HM}$ high magnification). 


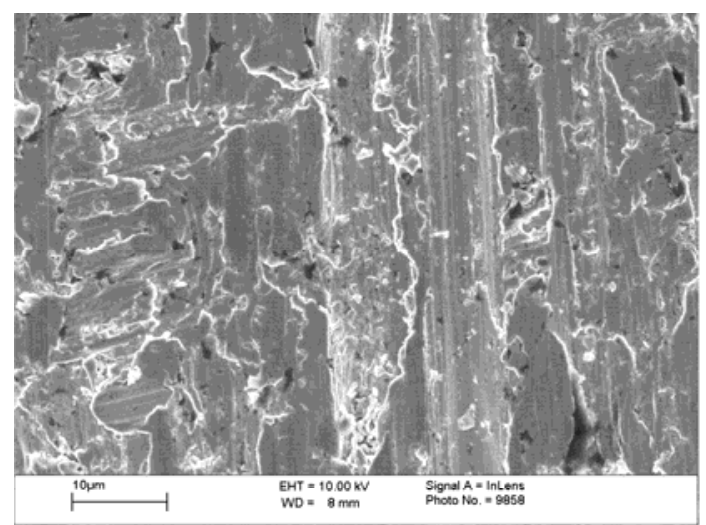

Mild steel, LM

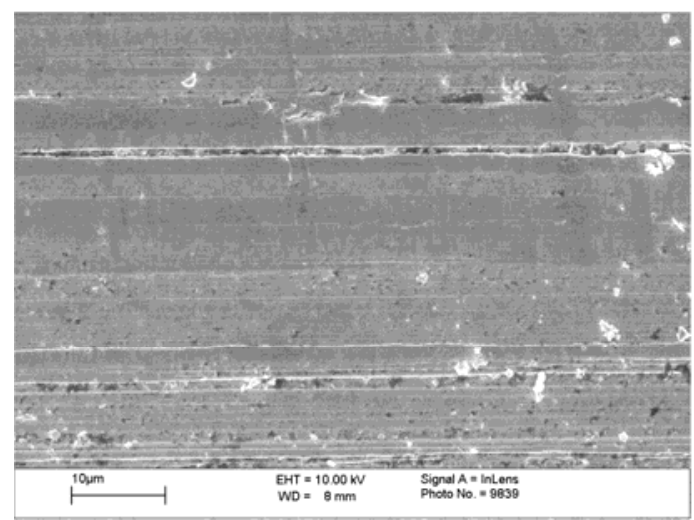

High strength steel, LM

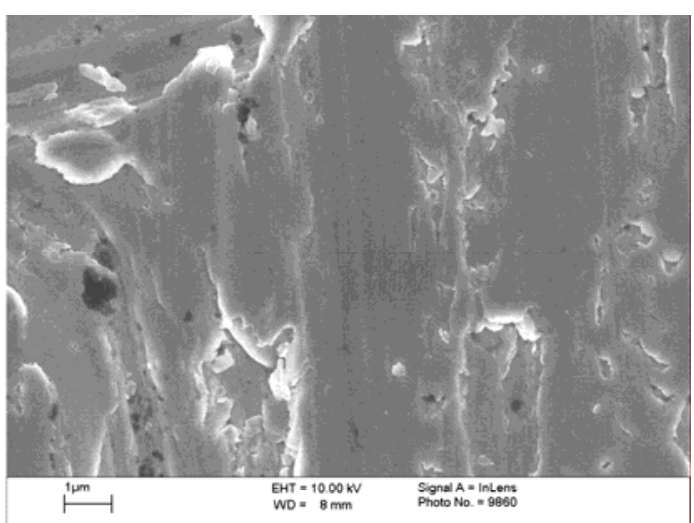

Mild steel, HM

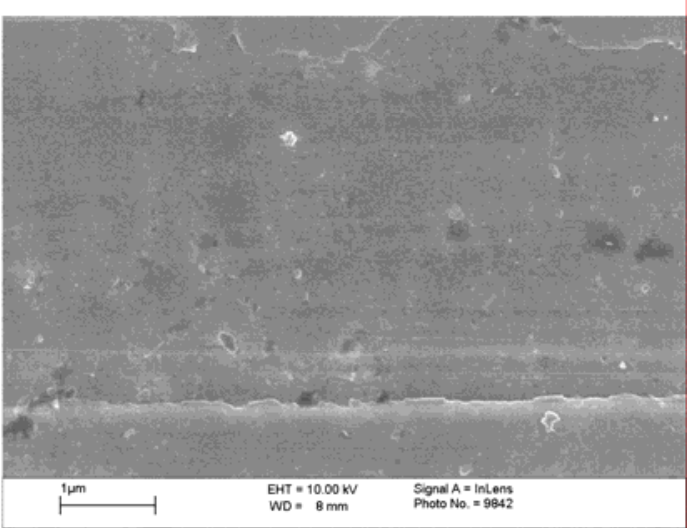

High strength steel, HM

Figure 6 SEM images for P treatment of different steels (LM low magnification and HM high magnification). 


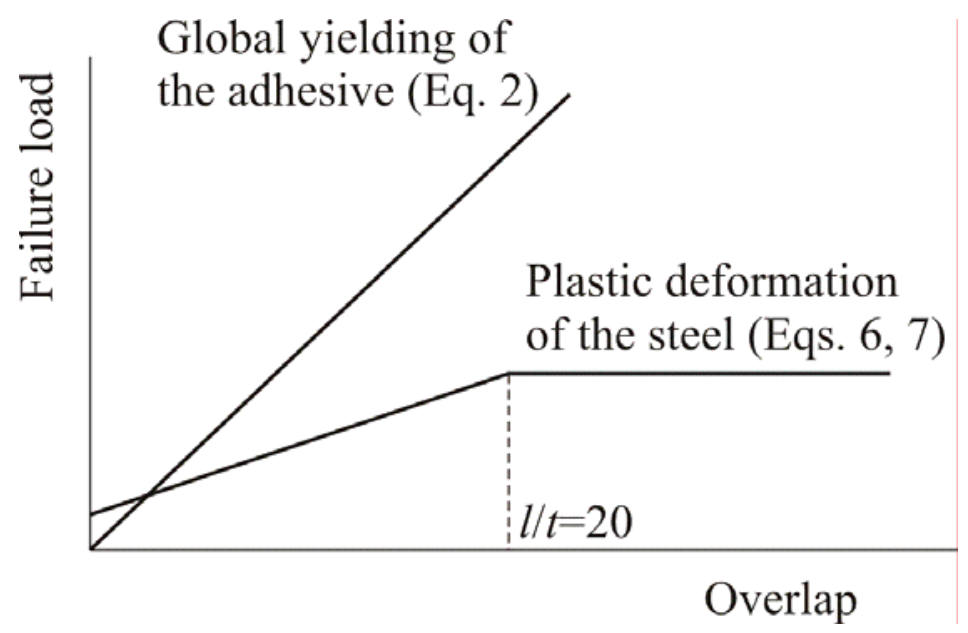

Figure $7 \quad$ Methodology to predict the failure load of single lap joints as a function of overlap based either on the global yielding of the adhesive or on the plastic deformation of steel.

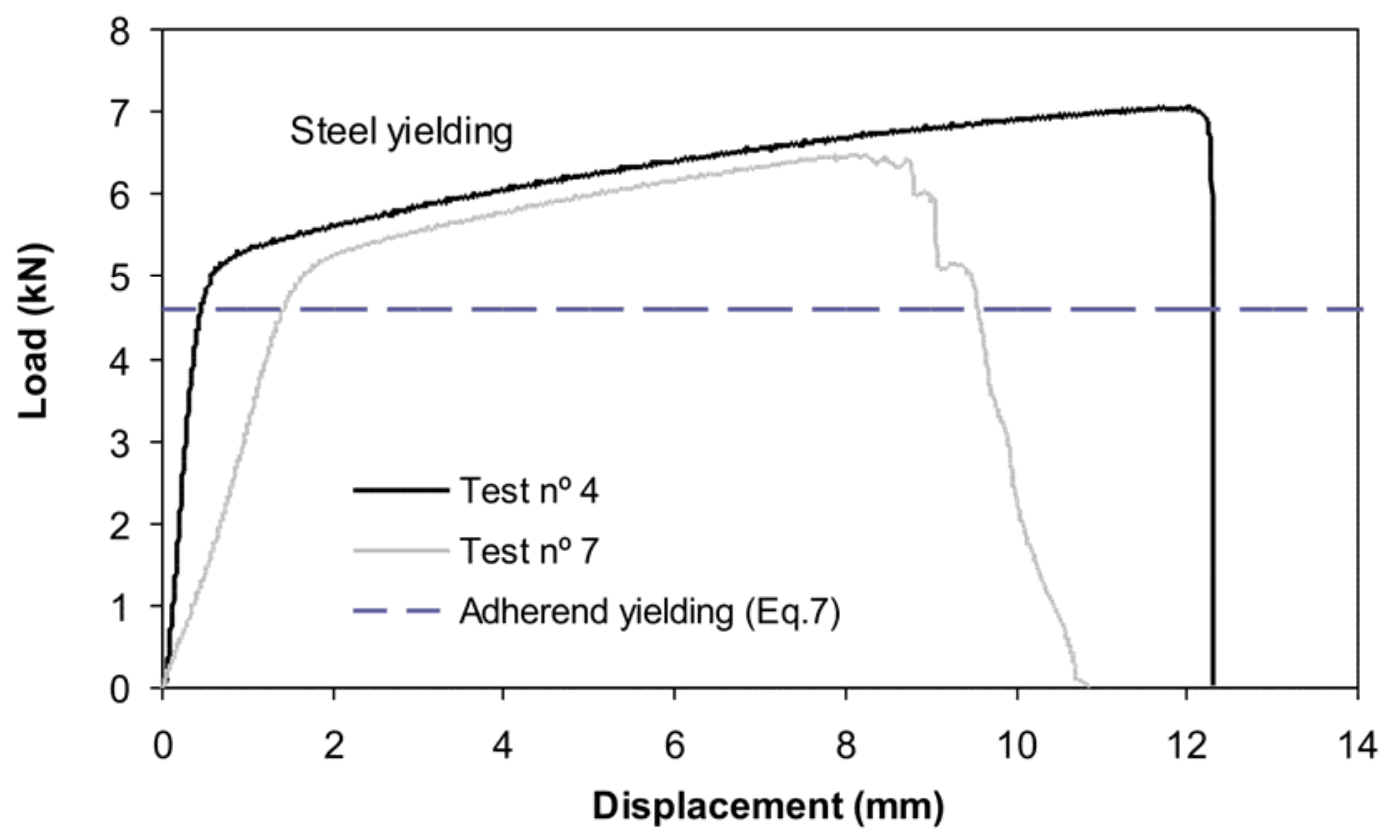

Figure 8 Load-displacement curves for tests $n^{\circ} 4$ and 7 (see Table 3) and adherend yielding prediction using Equation 7. 


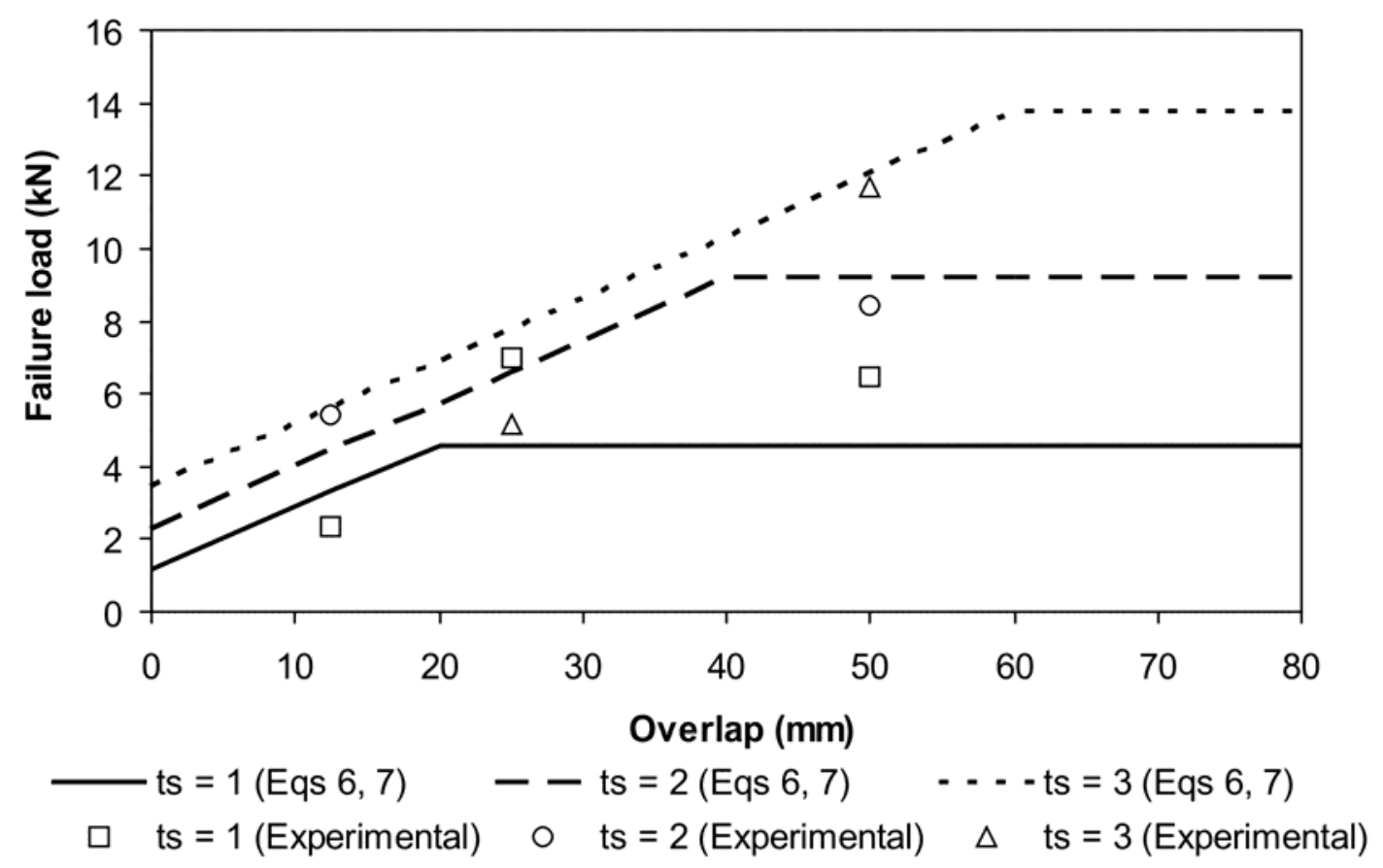

Figure 9 Experimental points corresponding to mild steel along with the three curves corresponding to the predictions for $t_{s}=1,2$ and $3 \mathrm{~mm}$ using Equations 6 and 7 (adherend plastic yielding).

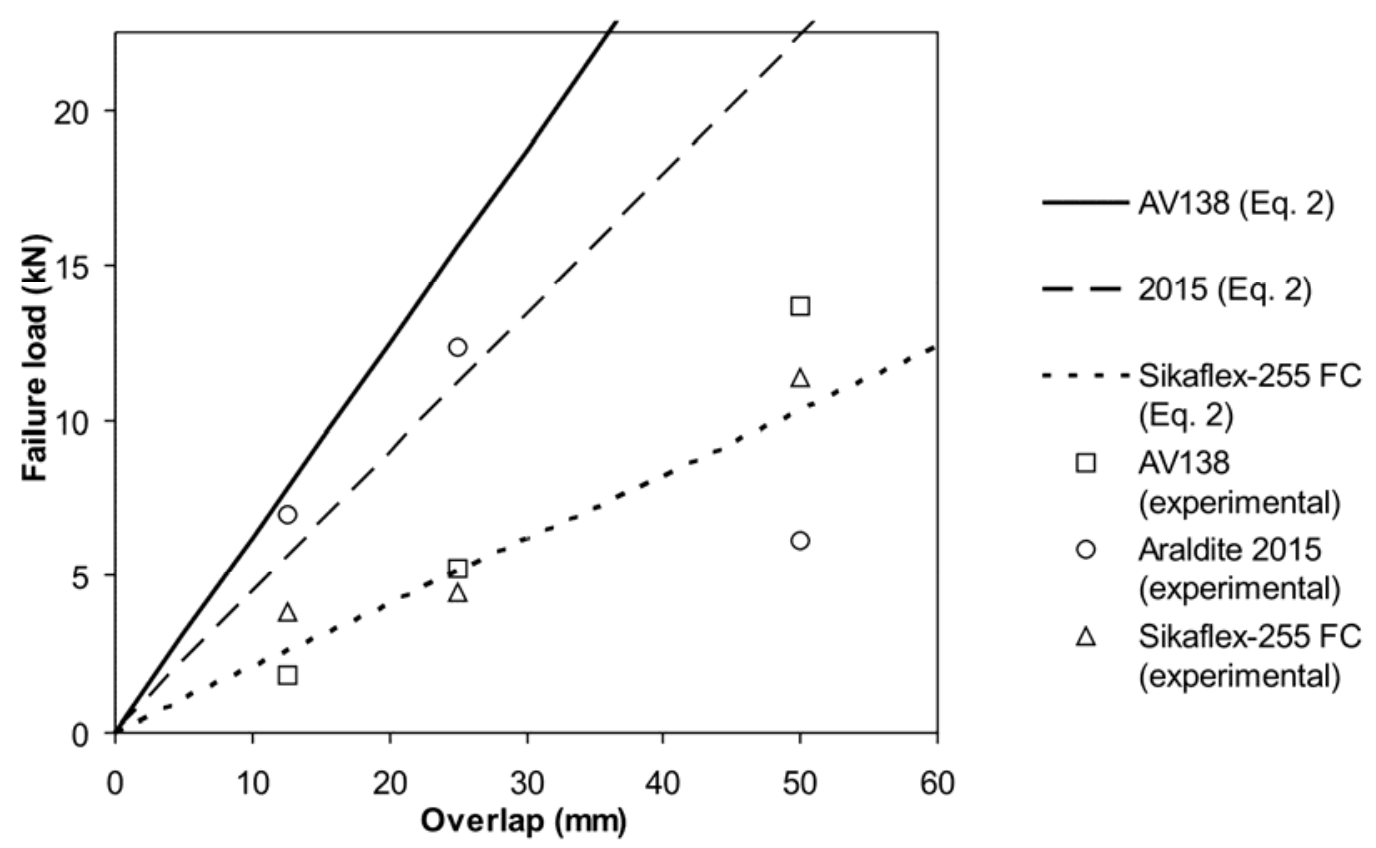

Figure 10 Experimental points corresponding to hard steel along with the three curves corresponding to the predictions for adhesives 2015, AV 138 and Sikaflex-255 FC using Equation 2 (adhesive global yielding). 


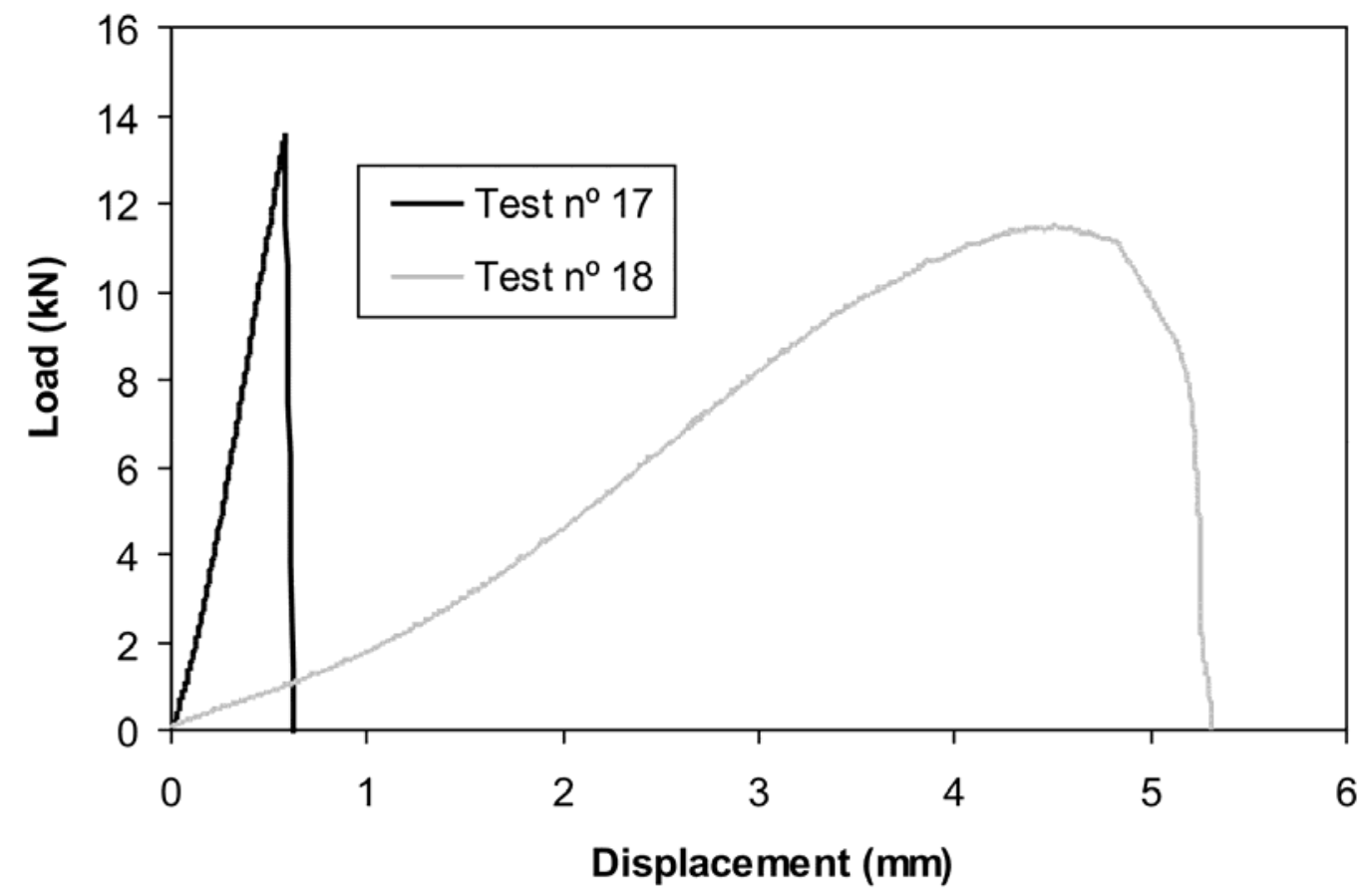

Figure 11 Load-displacement curves for test $\mathrm{n}^{\mathrm{o}} 17$ and 18 (see Table 3)

a)
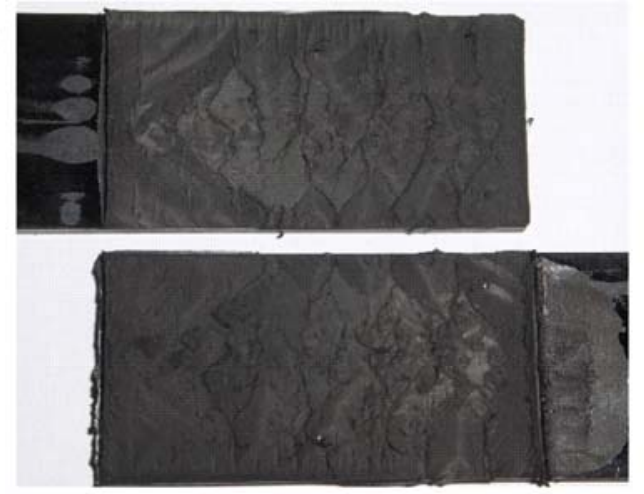

b)

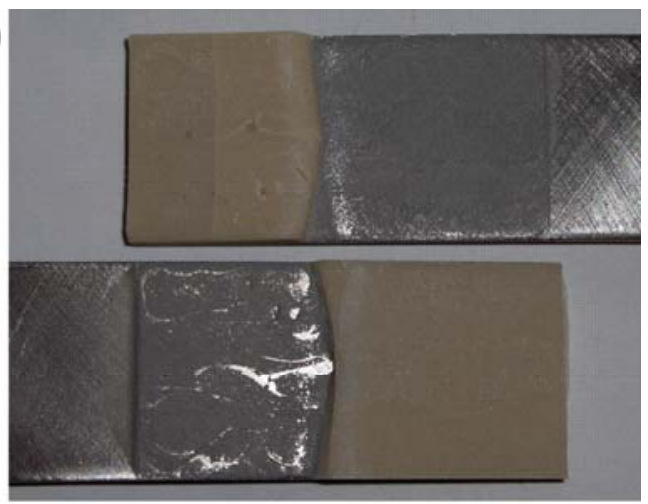

c)

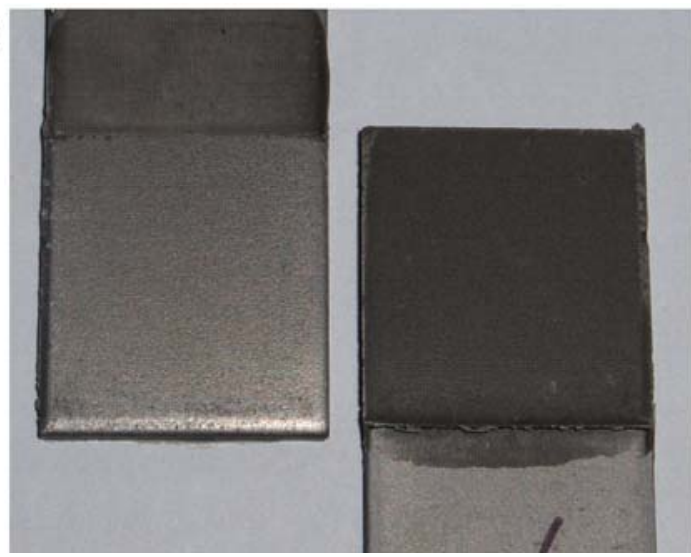

Figure 12 Failure surfaces; a) cohesive (test $\left.\mathrm{n}^{\mathrm{o}} 18\right)$; $\mathrm{b}$ ) cohesive close to the interface (test $\left.\mathrm{n}^{\circ} 8\right)$; c) adhesive (test $\mathrm{n}^{\mathrm{o}} 5$ ). 


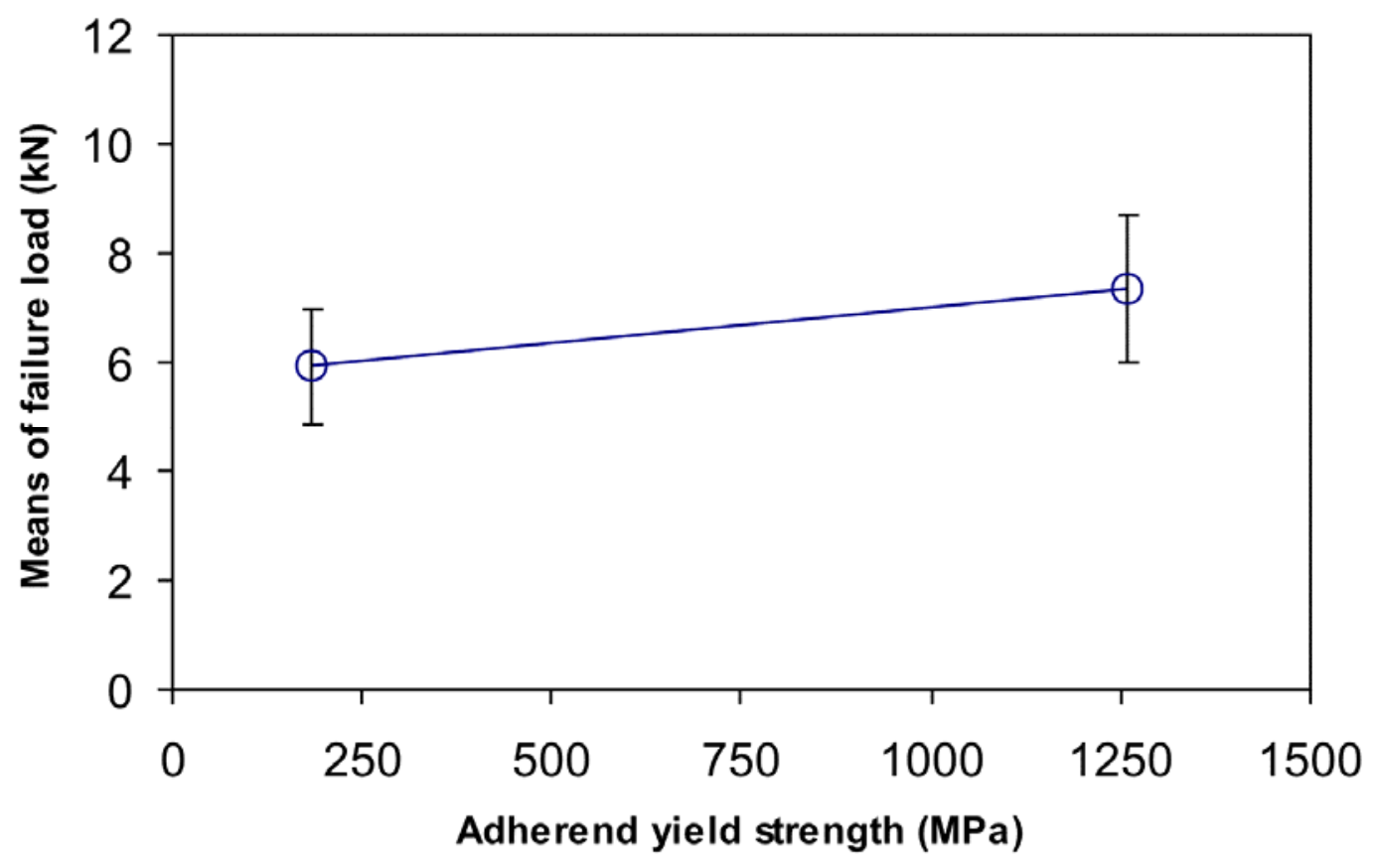

Figure 13 Average response graph with 95\% confidence error bars for the main effect of adherend yield strength.

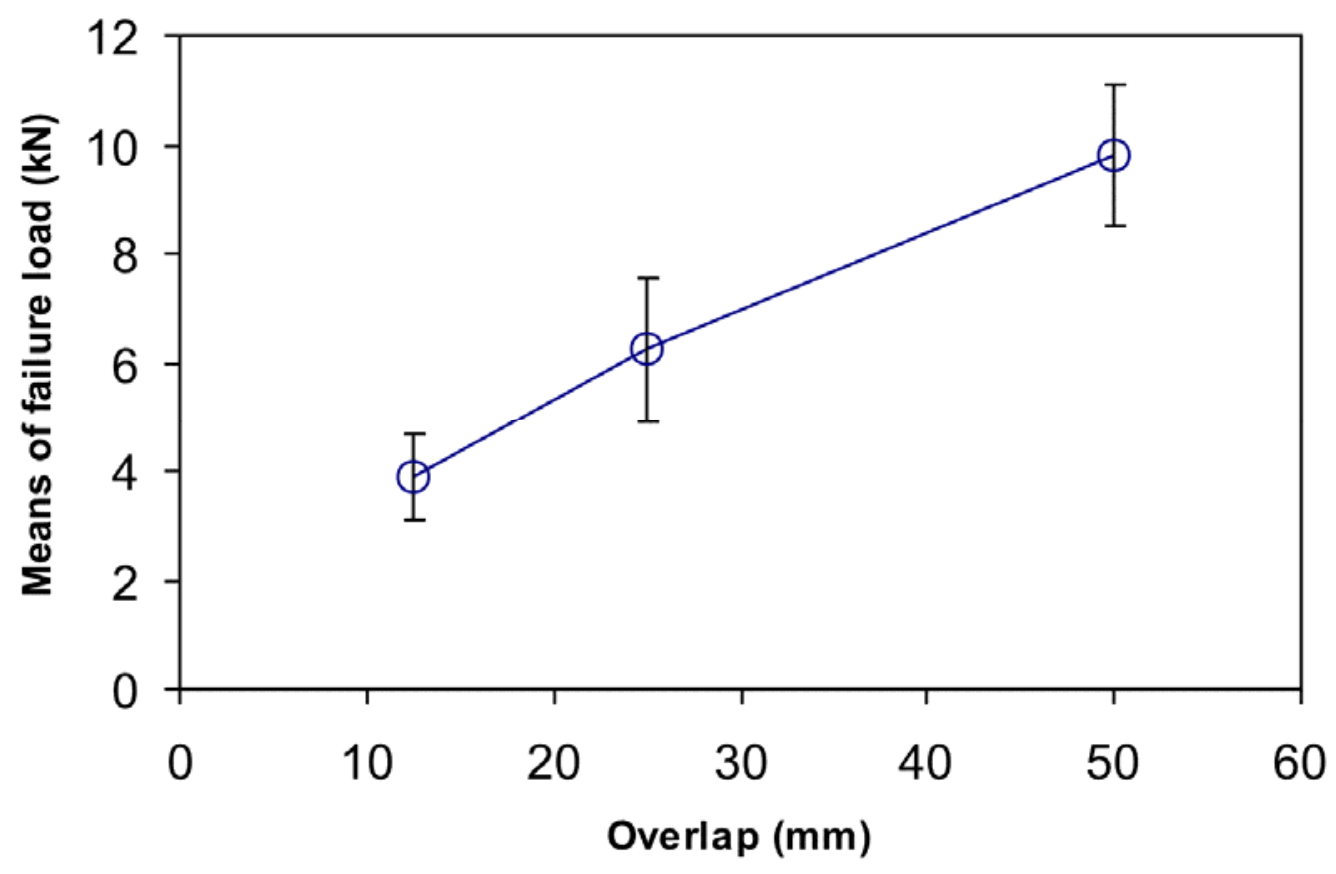

Figure 14 Average response graph with $95 \%$ confidence error bars for the main effect of the overlap. 


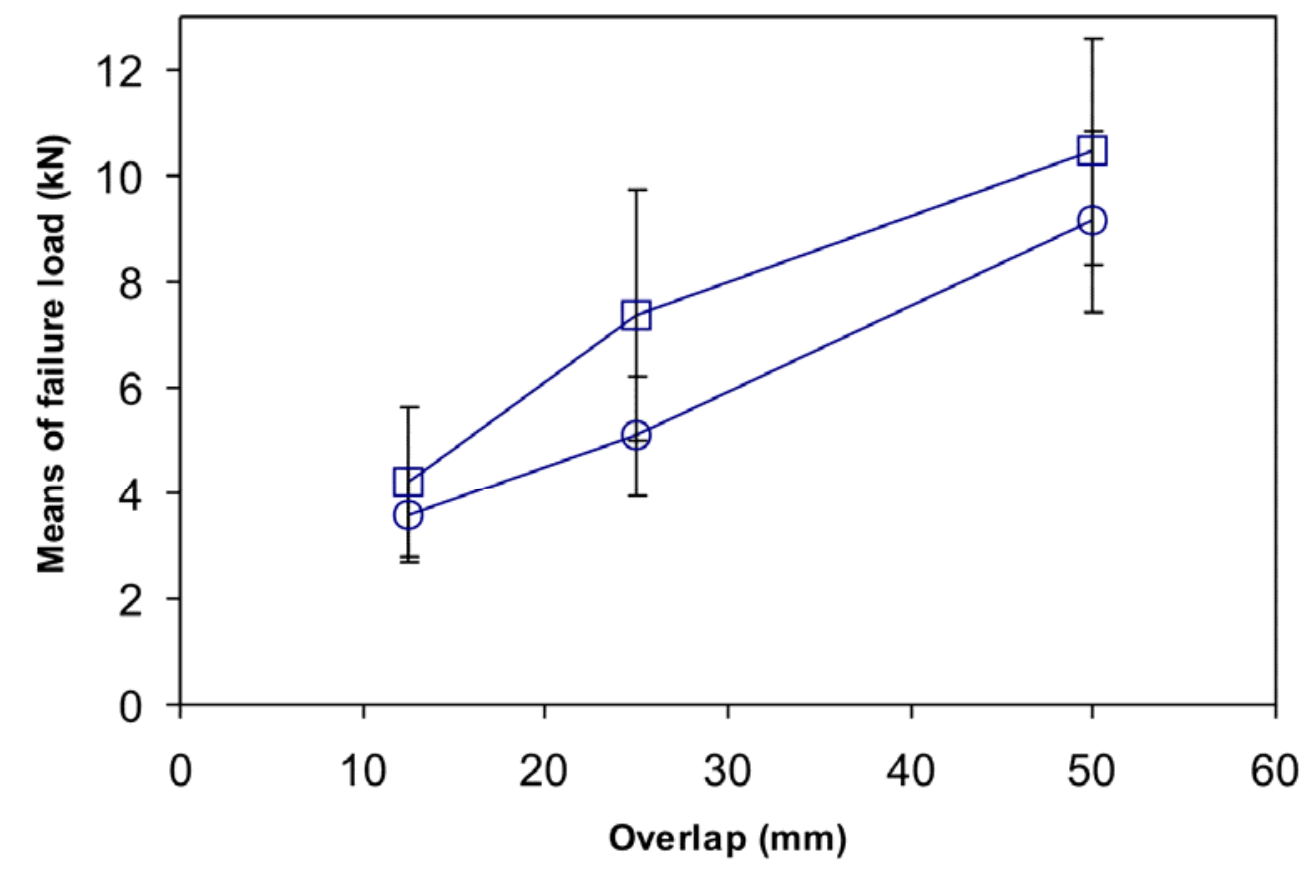

$\bigcirc$ - Low strength steel (184 MPa)

$\square$ High strength steel (1260 MPa)

Figure 15 Average response graph with 95\% confidence error bars for the main effect of the interaction adherend yield strength * overlap.

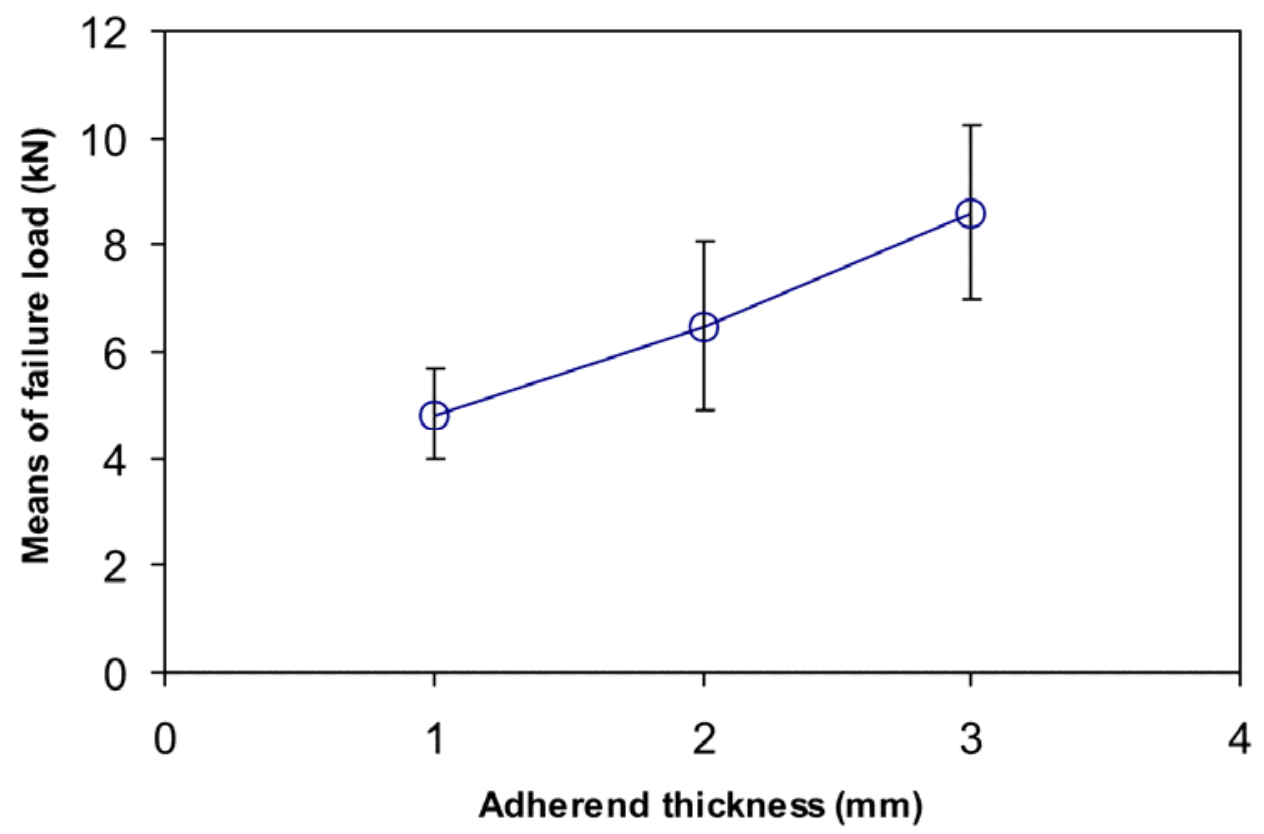

Figure 16 Average response graph with 95\% confidence error bars for the main effect of the adherend thickness. 


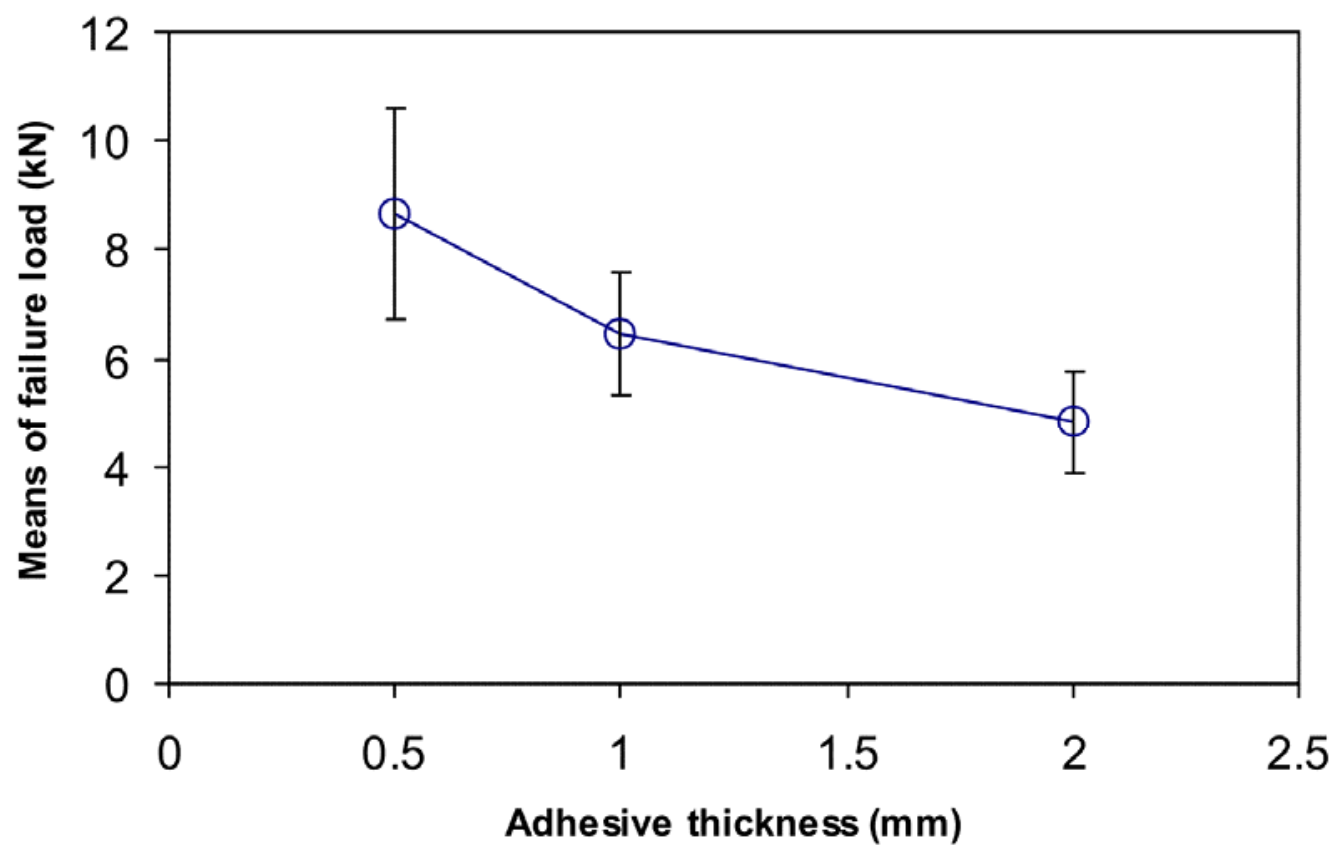

Figure 17 Average response graph with 95\% confidence error bars for the main effect of the adhesive thickness.

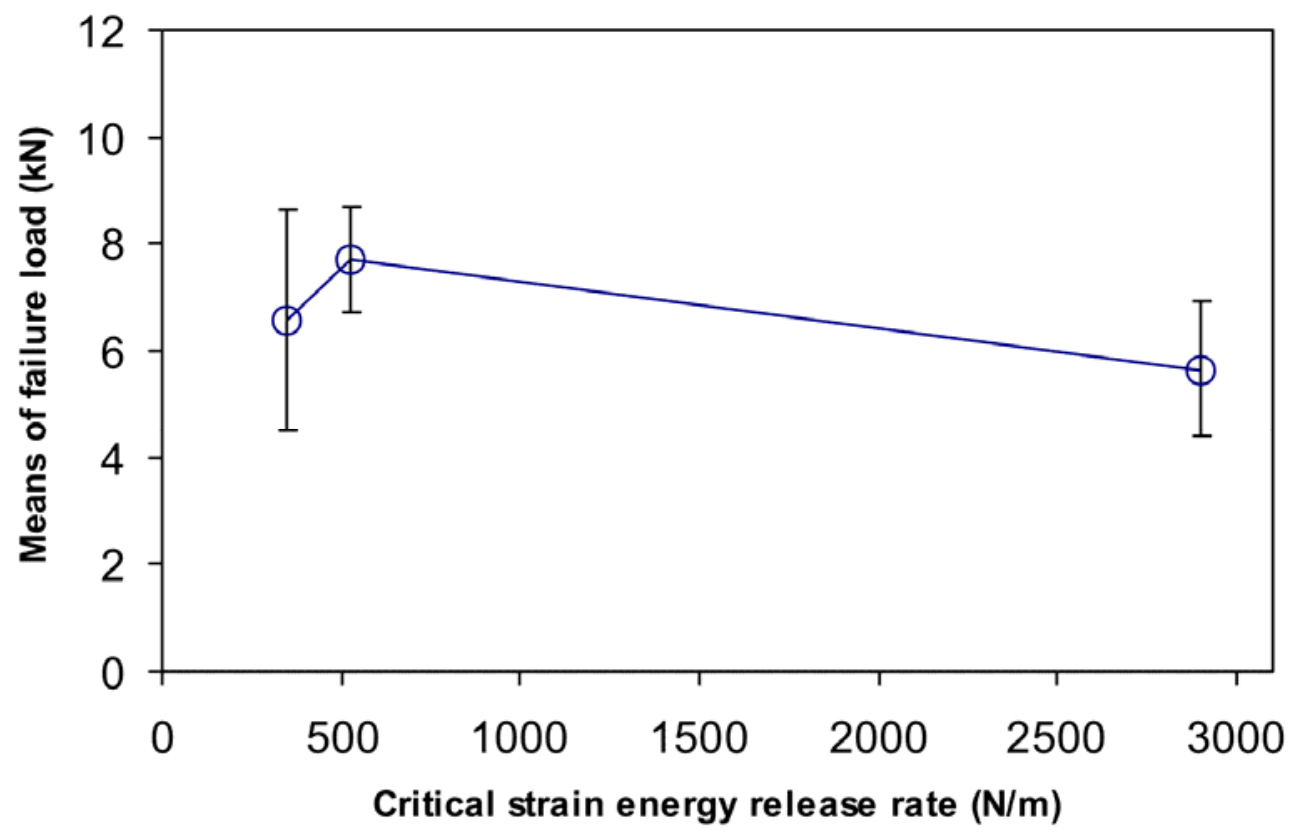

Figure 18 Average response graph with 95\% confidence error bars for the main effect of the adhesive toughness. 


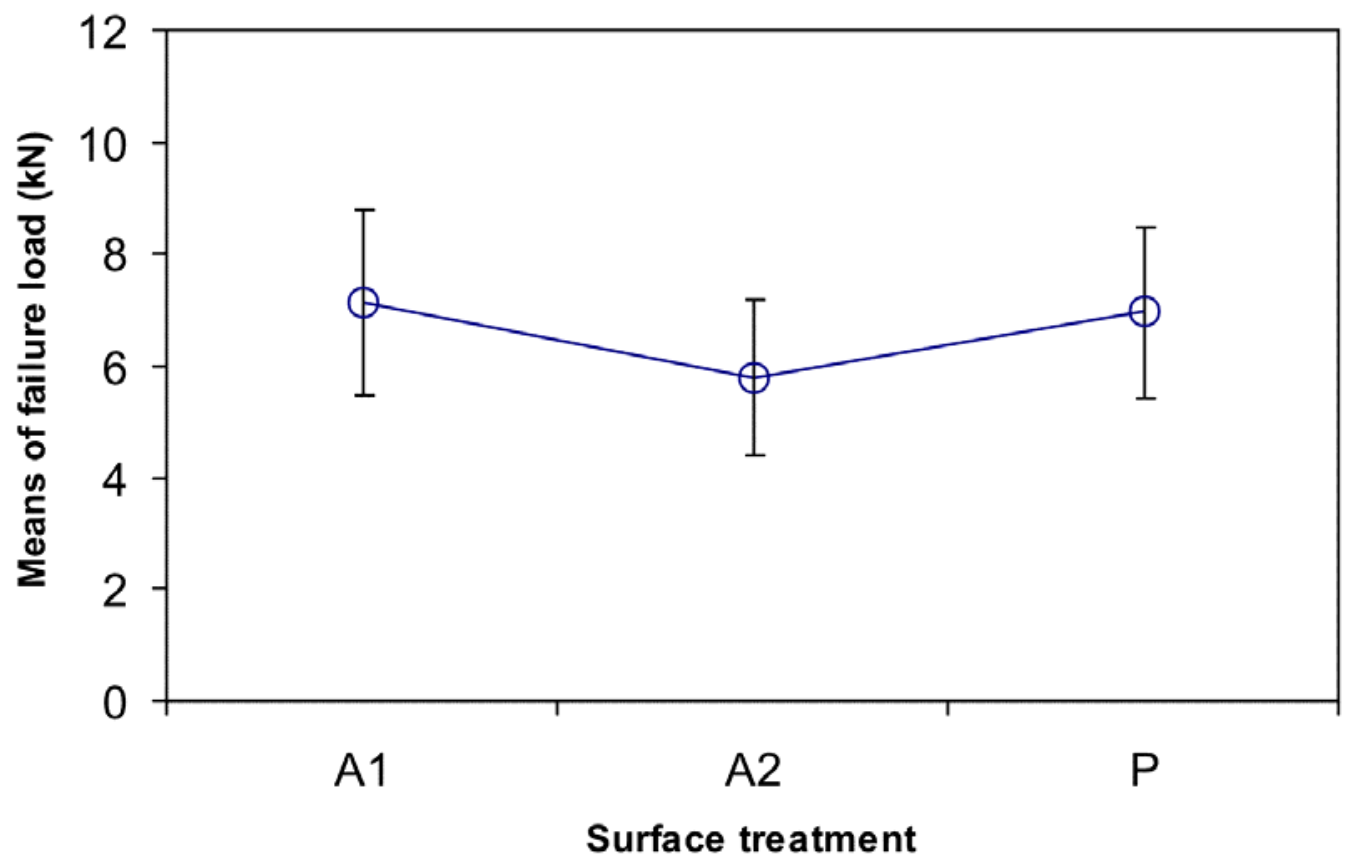

Figure 19 Average response graph with 95\% confidence error bars for the main effect of the surface treatment.

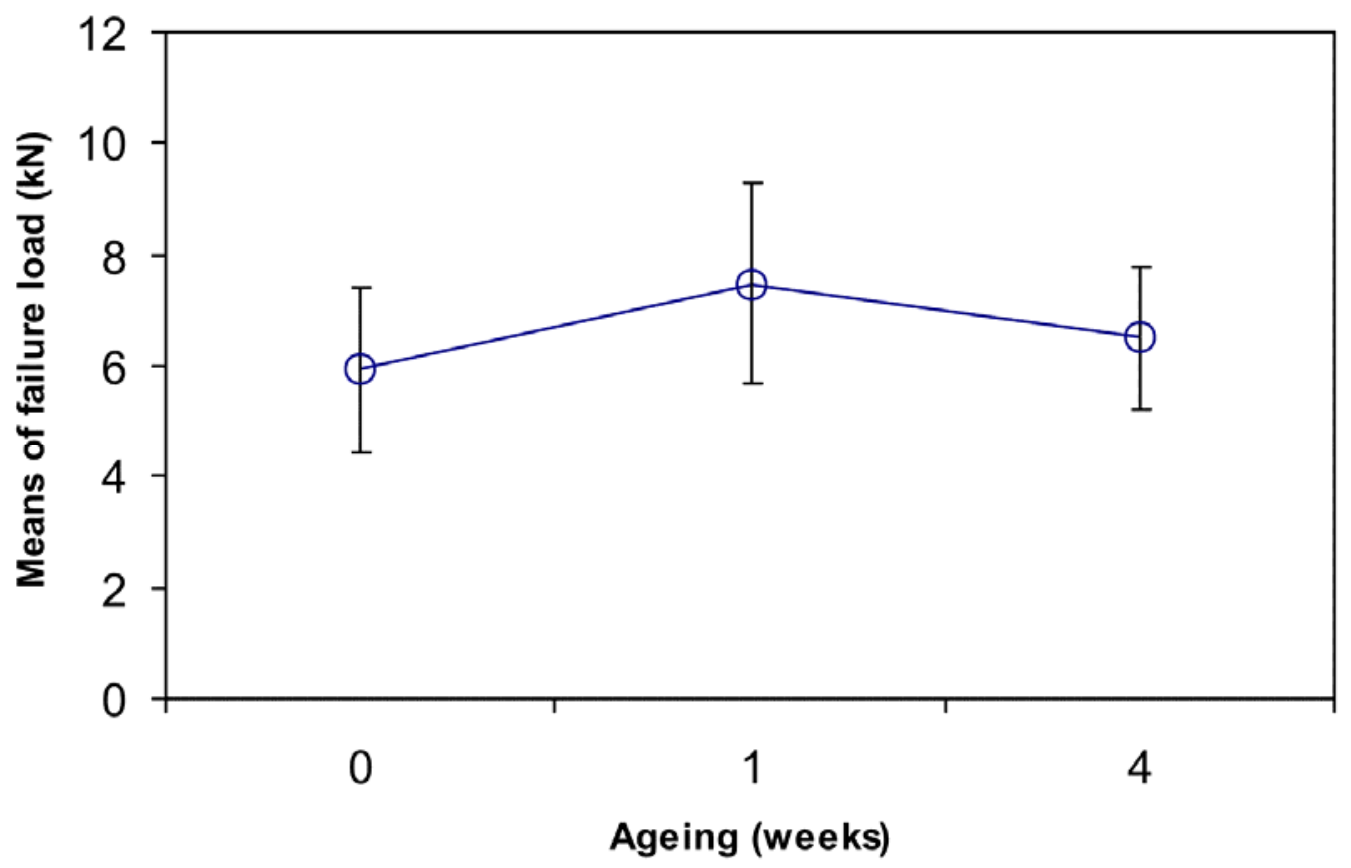

Figure 20 Average response graph with 95\% confidence error bars for the main effect of the durability. 


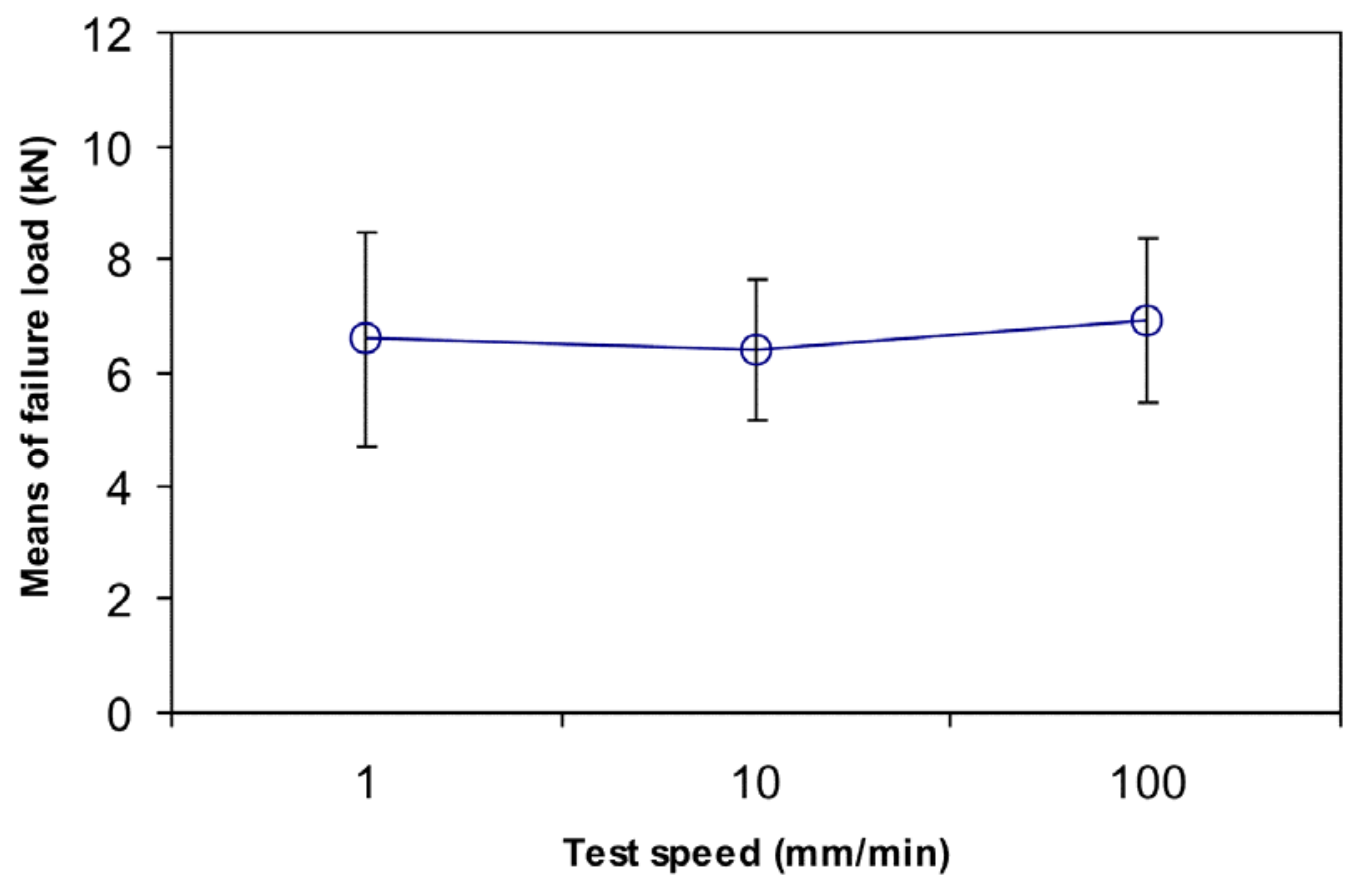

Figure 21 Average response graph with 95\% confidence error bars for the main effect of the test speed. 